\title{
¿Pueblos indígenas S. A.? \\ La cultura como política y propiedad en la bioprospección farmacéutica
}

\author{
Shane Greene \\ Universidad de Indiana, Bloomington
}

\begin{abstract}
Resumen
[ L DEBATE RECIENTE SOBRE LAS RECLAMACIONES INDÍGENAS ACERCA DE LA PROPIEDAD [ intelectual y cultural revela una serie de estrategias de movilización indígena que, simultáneamente, toman de y se mueven en contra de la lógica del mercado. A este respecto, son muy importantes varias estrategias indígenas usadas en las actividades de bioprospección actuales. Este artículo presenta datos de campo sobre un controvertido proyecto etnofarmacéutico entre los aguaruna peruanos, y un análisis comparativo sobre los resultados, prestando atención a varios casos en y por fuera de Sudamérica. Plantea preguntas sobre las formas de legitimar la autoridad dentro del creciente movimiento indígena, el papel de las ONG, los investigadores, las burocracias y las corporaciones en este proceso, y los dilemas que surgen de la politización y privatización de la cultura e identidad indígenas.
\end{abstract}

PALABRAS ClAVE: indígenas aguaruna, movimiento indígena, propiedad intelectual, farmacéuticas, mercado, bioprospección.

\section{Abstract}

THE ONGOING DEBATE OVER INDIGENOUS CLAIMS TO INTELLECTUAL AND CULTURAL PROPERTY reveals a series of indigenous strategies of mobilization that both appropriate from and work against the logic of the market. Of particular significance in this regard are the various indigenous strategies used in contemporary pharmaceutical bioprospecting activities. This article presents field data on a controversial ethnopharmaceutical project among the Aguaruna of Peru's high forest and offers a comparative analysis of the outcomes with attention to several other cases in and beyond South America. In particular, questions are raised about the forms of legitimating authority in the burgeoning international indigenous movement, the role of NGOS, researchers, bureaucracies, and corporations in this process, and the dilemmas that emerge from the politicization and privatization of indigenous culture and identity.

KEY wORDS: Aguaruna, indigenous movements, intellectual property, pharmaceuticals, markets, bioprospecting.

\footnotetext{
Revista Colombiana de Antropología

Volumen 42, enero-diciembre 2006, pp. 179-221
} 


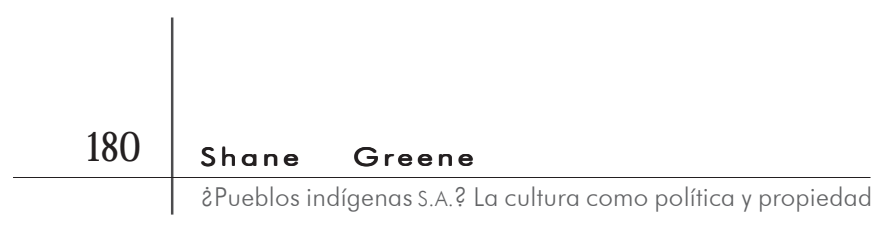

A VIEJA TRADICIÓN EUROAMERICANA QUE IMAGINA POR SIEMPRE A LOS pueblos indígenas al borde del colapso cultural y la destruc- ción demográfica, bien sea en las ideologías coloniales del proceso civilizatorio, la literatura antropológica sobre la aculturación o las políticas de desarrollo que prometen el triunfo inevitable de la modernización sobre la tradición, ha probado ser muy engañosa. Los sujetos nativos de la expansión imperial europea, las comunidades étnicas y tribales que aún subsisten en los estados-nación modernos, y los “obstáculos” al desarrollo capitalista cargados de tradición, han demostrado ser ellos mismos actores de proporciones históricas. Ser indígena en nuestra era es mucho más que una cuestión de supervivencia cultural o el producto discursivo de la imaginación colonial o moderna: para una serie de poblaciones en todo el mundo, es una posición subjetiva históricamente válida, acompañada de una estrategia consciente de acción política, cultural e histórica efectiva, aun cuando todavía muy debatida*.

En las últimas décadas, uno de los fenómenos más notables al respecto han sido los esfuerzos cada vez más visibles de los

* Artículo publicado originalmente en la revista Current Anthropology, volumen 45 número 2, abril de 2004.

Current Anthropology y el autor autorizaron su publicación en español a la Revista Colombiana de Antropolo-

gía, sin costo alguno. Por razones de derechos de autor se excluyeron los comentarios al texto realizados por otros investigadores. El comité editorial de la Revista Colombiana de Antropología agradece a Current Anthropology y al autor su autorización. Traducción de Santiago Giraldo, Instituto Colombiano de Antropología e Historia. pueblos indígenas de distintas regiones del mundo para formalizar sus propias formas de lucha y representación política, local, nacional y globalmente (véanse, Albó, 1991; Ballón Aguirre, 1988; Brown, 1993 Brysk, 2000; Chirif, García y Smith, 1991; Ewen, 1994; Friedman; 1999, Greene, 2002; Kearney y Varese, 1995, Montejo, 2002; Muehlebach, 2001; Niezen, 2003 Ramos, 1998; Smith, 1996; Smith y Ward, 2000; Urban y Sherzer, 1991; Warren y Jackson, 2002). En este proceso han formado una red institucional de activistas indígenas, organizaciones y personal de apoyo de alcance global. El foro más importante y visible internacionalmente de los voceros a favor de los grupos indígenas es el Grupo de Trabajo de las Naciones Unidas sobre Pueblos Indígenas, que dirige debates sobre la definición de "indígena" y redacta proyectos legislativos sobre los derechos territoriales, la autodeterminación, el medio ambiente y la cultura (Muehlebach, 2001; Niezen, 2003). Las actividades del grupo de trabajo de la Organización de las 


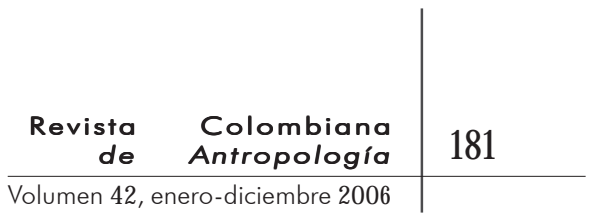

Naciones Unidas (ONU) y la visibilidad creciente de los movimientos indígenas se citan con frecuencia como prueba de que los pueblos indígenas han ganado una "voz" dentro de la política nacional e internacional (Ewen, 1994; Montejo, 2002; Muehlebach, 2001). Ante la idea de una "voz," surge de inmediato la pregunta de quien está hablando por quien y ante quien; en consecuencia, para todas estas formas emergentes de movilización indígena se vuelven fundamentales las cuestiones de autorepresentación indígena y el rol que cumplen las personas y organizaciones que actúan como mediadores entre los intereses externos y los locales.

La mediación política y cultural no es nada nuevo en el encuentro entre los pueblos indígenas y los proyectos de los colonizadores europeos o de los estados-nación modernos. Con frecuencia, para imponer las políticas coloniales a sus sujetos locales las administraciones coloniales dependieron en gran parte de los "jefes" nativos de algún tipo u otro. El papel de los kurakas nativos en Iberoamérica y el sistema de gobierno indirecto que usó jefes tribales en África son ejemplos clásicos (véanse, Comaroff y Comaroff, 1991: 255 Rasnake, 1988; Stern, 1982). El estudio de la mediación política indígena tampoco es nuevo en la antropología de los estados-nación modernos. El artículo de Eric Wolf sobre los líderes nativos mexicanos que actúan como "brokers" (intermediarios) culturales entre sus comunidades y la sociedad nacional es un clásico a este respecto.

Algunas de las controversias más significativas en la antropología contemporánea sugieren que la autorepresentación indígena, la movilización indígena global y la mediación que implican estas políticas interculturales están en el centro de buena parte de la antropología reciente. La muy controvertida relectura y revisión de David Stoll (1999) de la relación que hace la ganadora del premio Nobel de la paz, Rigoberto Menchú, sobre la vida como una indígena maya durante la guerra interna guatemalteca lo puso en el centro de un candente debate sobre su autoridad para cuestionar su representación como un icono indígena venerado internacionalmente. Aún más controvertido es el recuento crítico de Patrick Tierney (2000) acerca del trabajo de varios investigadores entre los yanomami venezolanos. El libro de Tierney incluye detalles sobre el intento del antropólogo Napoleón Chagnon de cuestionar el acto de representación política por parte de uno de los voceros más sobresalientes del 


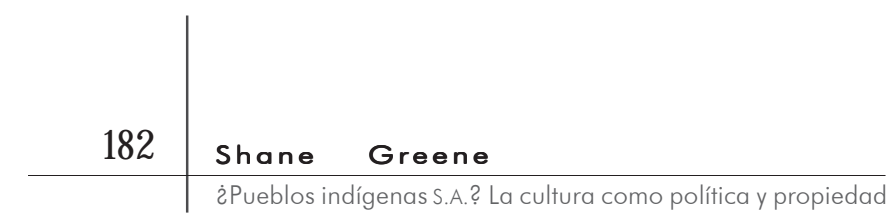

grupo, Davi Yanomami, a quien consideraba un peón de las organizaciónes no gubernamentales (ONG) ambientalistas y de sus propios rivales antropológicos (Graham, 2002).

Últimamente, estas controversias muestran cómo voceros indígenas y organizaciones representativas están negociando su papel de mediadores y representantes de las colectividades indígenas ante un amplio grupo de pueblos no-indígenas y organizaciones específicas a este momento histórico. Aun cuando los antropólogos y los misioneros siempre han sido interlocutores clave de los pueblos indígenas, ya no están solos en este debate, que de vez en cuando produce encuentros algo incómodos sobre la naturaleza del activismo indígena y lo que constituye la representación legítima. Las ONG ambientales y de derechos humanos, la burocracia estatal e internacional, las instituciones de desarrollo y financiación, las corporaciones, los investigadores y los activistas tienen sus propios intereses en negociar las políticas de representación indígena. Ciertamente, el activismo global internacional, los objetivos de las ONG transnacionales, las iniciativas de desarrollo sostenible e, incluso, el capitalismo "verde" que practican las corporaciones ambientalmente conscientes, se han convertido en agendas poderosas con respecto a los pueblos indígenas y sus formas de representación. Mediante tales contactos ambientalmente amigables, algunos líderes y organizaciones indígenas han comunicado con éxito sus dilemas a una audiencia global y a las poderosas instituciones financieras y de desarrollo (Carneiro da Cunha y de Almeida, 2000; Conklin y Graham, 1995 Smith, 1996; Turner, 1993). Sin embargo, muchos analistas anotan los riesgos en que se incurre al considerar a los pueblos indígenas como inherentemente conservacionistas y, como tal, estereotiparlos como "salvajes ecológicamente buenos" (véanse, Orlove y Brush, 1996: 334; Redford, 1990).

Dos fenómenos relacionados son arte y parte de esta movilización indígena más amplia y visible, y de la mediación de interlocutores no-indígenas: la politización de la cultura y su definición como propiedad. En una época en la que los antropólogos y otros estudiosos son cada vez más críticos acerca de los límites arbitrarios implícitos en el concepto de "cultura" (Gupta y Ferguson, 1992), los pueblos indígenas aceptan en público tales fronteras, citando las virtudes de las culturas indígenas de manera tal que las representan de una forma relativamente fija e identificable con colectividades/territorios delimitados e historias específicas 


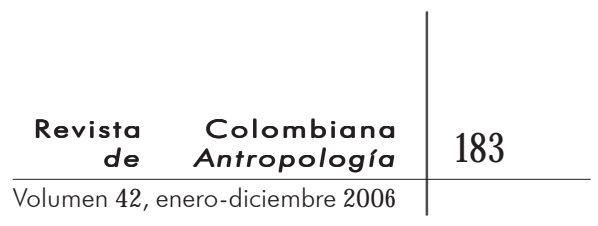

(Fischer, 1999). Ciertamente, los reclamos que se hacen sobre la existencia de culturas particulares y delimitadas le otorgan validez a las identidades subnacionales históricamente específicas sobre las que se basa la mayor parte de la política indígena global. Cada vez con mayor frecuencia, los representantes indígenas hablan sobre sus culturas como si fueran objetos alrededor de los que se organizara la lucha política en su esfuerzo por afrontar el legado de la ocupación colonial, la incorporación en los proyectos nacionales modernos y las presiones de la globalización.

La politización de la cultura indígena está acompañada por la tendencia a definirla como propiedad. En distintas partes del mundo, los representantes indígenas hablan con frecuencia sobre sí mismos no sólo como representantes de culturas particulares, sino también como copropietarios de culturas cuya propiedad es colectiva (Brown, 2003). Los reclamos indígenas contemporáneos sobre la propiedad cultural van desde lo material -restos humanos, artefactos, sitios significativos- hasta lo intangible-símbolos sagrados, música, héroes culturales, conocimientos sobre plantas tradicionales-. La lucha por convertir la cultura en propiedad es una de las esferas más activas en lo que se refiere al accionar político indígena y, arguyo yo, económico. Sin duda, en algunas instancias los reclamos sobre la propiedad cultural han sobrepasado en importancia las preocupaciones por el territorio y los derechos sobre la tierra, que históricamente han tenido gran importancia en las movilizaciones indígenas (Muehlebach, 2001). La sanción de la Native American Graves Protection and Repatriation-NAGPRA en 1990** le dio derechos sin precedentes a los indígenas estadounidenses para reclamar restos humanos y objetos parte de su cultura material que estuviesen en posesión de museos en los Estados

** NAGPRA: ley de protección y repatriación de tumbas de los nativos americanos. Esta ley tuvo consecuencias importantes en cuanto a las colecciones de materia óseo depositadas en museos y universidades, ya que debieron ser devueltas a los grupos que reclamasen los restos, al igual que cualquier objeto de significativa importancia ritual o ceremonial. Nota del traductor. Unidos (véanse, Haas, 1996;

Brown, 1998). Así mismo, también hay luchas significativas en torno al patrimonio cultural intangible. En el pleito entre los administradores del Crazy Horse Estate y la tribu rosebud sioux de Dakota del Sur, estos últimos demandaron con éxito el uso del nombre "Crazy Horse" en el mercadeo de un producto a base de licor de malta, y se llegó a un arreglo extraordinario: en 


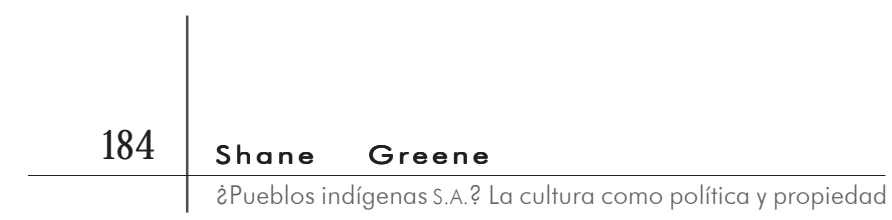

2001, SBC holdings pidió excusas formalmente y llegó a un acuerdo con los demandantes indígenas (Gale, 2001). En Sudáfrica, los pueblos san, que se han visto envueltos una serie de empresas de etnoturismo, presentaron una queja muy similar en relación con el uso inapropiado de su patrimonio cultural. Un grupo de !xûn san denunció a un fotógrafo sudafricano y a un hotel local por usar en un plegable turístico, sin autorización, una fotografía en la que aparecía un líder san fallecido (Sylvain, 2002: 1080).

Estos ejemplos sugieren que, por lo menos a cierto nivel, los pueblos indígenas están luchando por vigilar y ejercer un control más directo sobre su propiedad cultural, al desafiar y politizar su uso por parte de actores no indígenas. Sus motivaciones económicas parecen ser una preocupación de segundo orden. Por ejemplo, el caso Crazy Horse no involucró daños monetarios, sino una compensación en términos culturalmente apropiados, tales como caballos de carreras, trenzas de tabaco y pasto dulce (sweetgrass) y cobijas Pendleton (Gale, 2001). Estas estrategias, encaminadas a reclamar los elementos tangibles e intangibles de su cultura de las manos de no indígenas -por ejemplo, corporaciones, museos, investigadores, agencias turísticas- y de retirarlos del dominio público, giran alrededor, sobre todo, del aparente sacrilegio y profanación que supone el uso inapropiado, la posesión, la exhibición y la explotación comercial de estos elementos.

La búsqueda contemporánea de la utilidad científica-comercial en los recursos biológicos mundiales, conocida como bioprospección, enfrenta una serie de problemas similares en lo que respecta a los reclamos indígenas sobre el conocimiento médico tradicional entendido como propiedad intelectual o cultural. En esta esfera de prácticas y políticas, es posible observar la aparición de unas dinámicas que requieren de tanta atención en sus aspectos económicos como en lo que respecta al sacrilegio y la difamación. En este texto espero plantear una serie de preguntas sugestivas acerca de lo que está en juego cuando los representantes indígenas se toman en serio las aspiraciones económicas en las negociaciones sobre el valor potencial que puede tener el conocimiento médico tradicional en el mercado, y los nuevos problemas que emergen como resultado. En este sentido, me aparto de una antigua tradición estructural-funcionalista inspirada por Durkheim en la antropología. En vez de de concentrarme en los principios de linajes, descendencia, matri- 


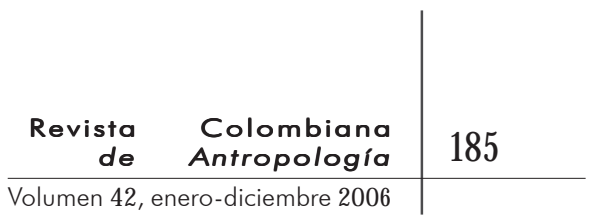

monio y demás que estructuran la organización social, me interesa el análisis de la política y la economía contemporáneas que dan pie a la aparición de estrategias empresariales e identitarias para la incorporación indígena en los reclamos sobre la propiedad cultural. ¿Cuáles son los dilemas políticos y económicos que emergen al considerar el conocimiento médico indígena como propiedad en una época de bioprospección farmacológica y búsqueda del desarrollo sostenible? Y, ¿a qué tipo de dilemas se enfrentan cuando los propietarios culturales exclusivos deben ser definidos en términos legales en un escenario que involucra las múltiples agendas y expectativas diferenciadas de los representantes indígenas, las corporaciones farmacéuticas, instituciones estatales, académicos, ONG y activistas de todo tipo?

\section{LA BIOPROSPECCIÓN FARMACÉUTICA $Y$ LOS RECLAMOS INDÍGENAS DE PROPIEDAD SOBRE EL CONOCIMIENTO TRADICIONAL}

A DÉCADA DE 1990 VIO RESURGIR EL INTERÉS PÚBLICO Y PRIVADO EN EL potencial que podían tener las fuentes basadas en plantas para la producción de nuevos productos farmacéuticos, después de la disminución continua de tales investigaciones a partir de mediados del siglo veinte. El Convenio de las Naciones Unidas sobre diversidad biológica (CDB), ratificado en 1992, es el principal instrumento normativo en lo que concierne a la bioprospección. En un esfuerzo por enfrentar las iniquidades Norte/Sur, desarrollado/en vías de desarrollo en la industria biotecnológica internacional, el Convenio reconoce el control soberano de cada estado sobre los recursos biológicos que se encuentran en sus territorios, considerados antes de dominio público universal o parte de la herencia común de la humanidad. Aún más. El artículo 8j del Convenio sugiere que los esfuerzos de bioprospección que utilicen los usos tradicionales de recursos biológicos que resulten exitosos en términos comerciales, deberían incluir la protección y repartición de utilidades para las poblaciones indígenas o locales cuyo conocimiento contribuye a la creación de productos de ingeniería biológica.

Las posibilidades que puedan tener estas drogas del futuro basadas en remedios tradicionales a base de plantas tienen sus 


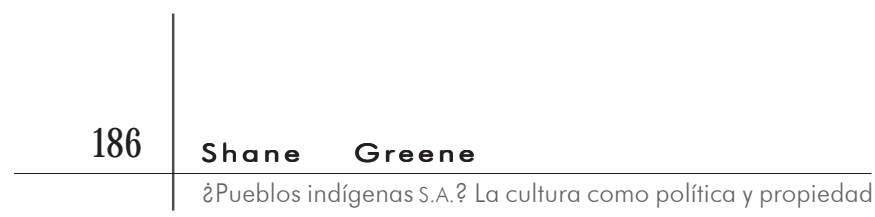

raíces, en gran parte, en varios ejemplos históricos, siendo los más citados la aspirina, los antibióticos y la quinina, entre otros. La idea de plantas medicinalmente valiosas se evoca con frecuencia al tiempo con imágenes de grupos indígenas, sus prácticas médicas tradicionales y las drogas milagrosas que, presumiblemente, están sin descubrir en las profundidades de los bosques tropicales (véanse, Goering, 1995 Dye, 2000). Sin embargo, no es del todo claro que el futuro de los medicamentos dependa de manera significativa de la bioprospección, y menos aún del conocimiento médico de los pueblos indígenas. Los diagnósticos más recientes (véanse, Albers-Schönberg, 1995, Artuso, 1997; Aylward, 1995 Macilwain, 1998; Moran, King y Carlson, 2001; O'Conner, 2000; Economist, 1999) no son tan optimistas como los emitidos a principios de la década de 1990.

En respuesta a las actividades más recientes de bioprospección $\mathrm{y}$ al Convenio de las Naciones Unidas, muchos han decidido conceptualizar el conocimiento tradicional como una nueva forma de propiedad intelectual (véanse, Boyle, 1996; Cox y Balick, 1994; Elisabetsky, 1991; King y Tempesta, 1994; Lewis et al.,1999, Plotkin, 1993, Rosenthal, 1997; Tobin, 19990,1994). Rosemary Coombe (1999, 1998) ha criticado esta posición, ya que, históricamente, la propiedad intelectual ha estado asociada a una ideología de individualismo posesivo y a la idea romántica de la autoría individual, características peculiares de y para las sociedades capitalistas. Sin embargo, ella es consciente del potencial político-retórico que tienen los reclamos sobre la propiedad intelectual cuando los hacen grupos indígenas subyugados históricamente, ansiosos de ganar algún control sobre las fuerzas del mercado que están transformando sus sociedades (1998: capítulo 5). Los activistas indígenas ofrecen diversas opiniones: algunos promueven con entusiasmo la idea del conocimiento tradicional como propiedad intelectual, mientras que otros la rechazan, considerándola una imposición de categorías occidentales sobre sus propias características culturales (véanse, Brush, 1999, Coombe, 1999). Las ONG ambientalistas, actores principales también en el debate sobre la bioprospección, con frecuencia se sitúan como un contrapeso a las tendencias abusivas de los intereses del capital transnacional y como aliados de los pueblos indígenas, locales y del tercer mundo en general.

Darrell Posey fue uno de los primero antropólogos en involucrarse y promocionar la idea del conocimiento tradicional como parte de la propiedad colectiva intelectual de los grupos indígenas 


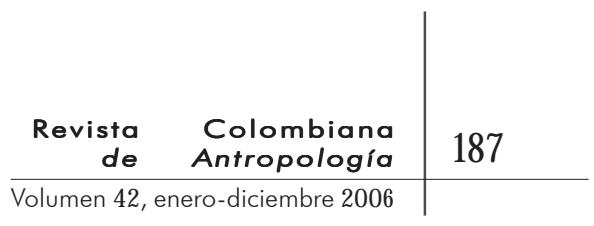

(Posey, 1990) ${ }^{1}$. Desde entonces, otros antropólogos han encontrado problemática la exclusividad y delimitación arbitrarias implícitas en la propiedad intelectual, su historia como instrumento legal en las sociedades capitalistas, la incompatibilidad de los sistemas de conocimiento culturalmente fluidos y colectivos no occidentales con las leyes occidentales exclu-

1 El trabajo de Posey introdujo a los antropólogos en el debate sobre la biodiversidad y la ética de la apropiación etnobotánica del conocimiento médico tradicional para la investigación farmacéutica, justo antes de segundo Congreso internacional de etnobiología en 1990, en el que esta cuestión se discutió en profundidad. En una publicación posterior con Dutfield, Posey ubica la lucha indígena sobre el conocimiento tradicional y la propiedad intelectual dentro de la lucha más amplia sobre los derechos indígenas y de comunidades locales a recursos (Posey y Dutfield, 1996). sivas e individualizadas sobre la propiedad, y la amenaza que tal posición representa para el dominio público del conocimiento (véanse, Brown, 1998, 2003, Brush, 1994, 1996, 1999, Posey y Dutfield, 1996; Strathern, 1996). En relación con lo anterior, Dove (1995), Coombe (1999) y Greene (2002) sostienen, además, que muchos pueblos indígenas sufren más por problemas de pérdida e invasión territorial, desplazamiento y marginación por parte de sus propias élites estatales que por la apropiación de su conocimiento tradicional por parte de biopiratas del norte.

Gran parte de la literatura pionera sobre bioprospección y conocimientos tradicionales como propiedad intelectual está llena de polémicas y posiciones ideológicas. Los debates que sigan deben ser matizados mediante la evaluación a profundidad de casos particulares, las complicadas negociaciones asociadas a ellos y, como demuestra Cori Hayden (2003, s. f.), el que los bioprospectores buscan, cada vez con mayor frecuencia, evitar tales negociaciones. Con base en mis propias investigaciones en campo y documentos relacionados, examino un ejemplo controvertible de las negociaciones sobre bioprospección farmacéutica por parte del pueblo aguaruna de la amazonia peruana. El amazonas es un contexto particularmente bueno para tal evaluación, dada su posición central en gran parte del debate contemporáneo sobre la bioprospección, el activismo indígena y ambiental y la protección de la propiedad cultural (véase, por ejemplo, Conklin, 2002). Compararé el caso aguaruna con otros relacionados en y por fuera del amazonas, en un intento por formular algunas conclusiones preliminares sobre los dilemas de la representación e incorporación indígenas, y los reclamos contemporáneos relacionados con la cultura como propiedad. 


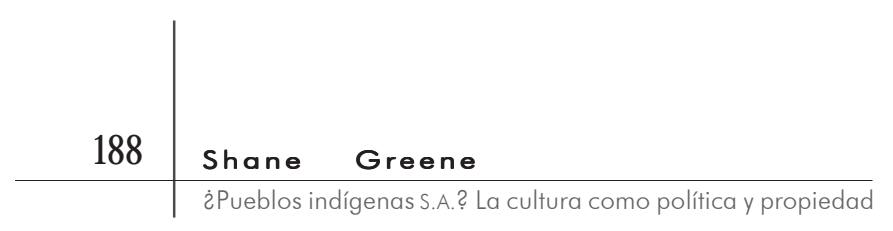

LAS NEGOCIACIONES

ENTRE EL INTERNATIONAL COOPERATIVE Biodiversity Group y LOS AgUARUNA: PRIMER ASALTO

$\bigcup$ NO DE LOS EJEMPLOS MÁS CITADOS DEL RENOVADO INTERÉS EN LA biprospección es el programa de becas públicas International Cooperative Biodiversity Group (ICBG) ${ }^{2}$, resultado de un taller realizado en 1991, y que contó con el patrocinio del National Institute of Health (NIH), la National Science Foundation (NSF) y la United States Agency for Internacional Development (Usaid) de los Estados Unidos. El NIH se constituyó en el administrador del programa y anunció un concurso por grandes becas de investigación sobre el potencial farmacéutico de la biodiversidad internacional. De acuerdo con Rosenthal (1997: 281-282) el programa ICBG es esencialmente "experimental”, ya que la utilidad farmacéutica de la biodiversidad está lejos de ser comprobada, y está diseñado para funcionar con metas que son una clara

2. Otras formas de bioprospección, como la agroindustrial o genética, están ligadas al debate más amplio sobre la biodiversidad y el acceso y la propiedad de los recursos biogenéticos. Aun cuando la adquisición de nuevas variedades de semillas constituye, en apariencia, la mayor parte de las prácticas de la industria agrícola (véase, Brush, 1999, en todos los casos esto involucra también el acceso a la innovación humana asociada a ella -por ejemplo, las prácticas de cultivo-. En cambio, en la bioprospección farmacéutica muchas compañías e investigadores prefieren usar una metodología de colectas al azar o taxonómicas para el material biológico, en vez de los métodos etnobotánicos que requieren del conocimiento tradicional y el respeto por los derechos indígenas (véanse, Aylward, 1995, Moran King y Carlson, 2001: 506.

3 Estados Unidos no firmó la Convención, y la mayoría de las interpretaciones acerca de sus razones para rehusarse a firmarla asumen que las medidas a favor de la repartición de utilidades y la soberanía nacional representaban una amenaza en potencia para los intereses corporativos de ese país sobre los recursos biológicos extranjeros. Sin embargo, esto no concuerda con la aparición, casi simultánea, del programa ICBG, que toma en cuenta los principios básicos de la Convención. respuesta a los pricipios delineados en la Convención de las Naciones Unidas ${ }^{3}$. En 1993 y 1998 se otorgaron dos rondas de becas ICBG, a ocho equipos de investigación con investigadores principales provenientes de universidades o institutos de salud estadounidenses (véase el portal de internet del ICBG: www.nih.gov/fic/opportunities/icbg.html). Las becas del ICBG se basan en la cofinanciación, coinvestigación y relaciones mutuamente beneficiosas entre instituciones, socios comerciales $\mathrm{y}$, en algunos casos, comunidades específicas locales/ indígenas de Estados Unidos y países en vía de desarrollo. La solicitud para obtener becas del ICBG (1997: 17) promueve la "participación activa" de 


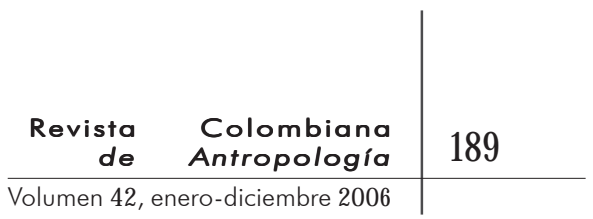

patrocinadores del sector corporativo, obligando así a los becarios potenciales a buscar socios en el sector privado.

En 1993, un equipo de la Universidad de Washington, encabezado por el etnobotánico Walter Lewis, recibió una beca del ICBG debido a la recolección de muestras botánicas en colaboración con los aguaruna, grupo amazónico con una población bastante grande -4513 de acuerdo con el censo de 1993- que habita la parte alta de la selva peruana, cerca a la frontera con Ecuador. Los aguaruna, cuya reputación como guerreros es de vieja data, han estado al frente de la organización política entre los indígenas amazónicos desde la década de 1970. La gran mayoría de las ciento ochenta y siete comunidades aguaruna con títulos de propiedad sobre sus tierras están afiliadas, con disitintos grados de lealtad y participación, a organizaciones administradas por los mismos aguaruna o, en algunos casos, a organizaciones coadministradas con otros grupos étnicos: los huambisa y los chayhuita. En 2004 identifiqué por lo menos trece organizaciones de este tipo, la más reciente de las cuales se había conformado en 2002. Las organizaciones locales coordinan sus actividades con o son consideradas filiales locales de alguna de las dos grandes confederaciones indígenas nacionales, que tienen su base en Lima. Todo esto hace que exista una serie de complicadas alianzas políticas y divisiones en el colectivo aguaruna, algo que los investigadores del ICBG descubrieron pronto.

Según los protocolos del ICBG, la investigación de la Universidad de Washington se hizo en sociedad con instituciones peruanas e indígenas. Los cuatro socios eran la Universidad de Washington, la Universidad Peruana Cayetano Heredia (UPCH), el museo de Historia Natural de la Universidad de San Marcos, y una categoría denominada como "el pueblo aguaruna". Miembros de las tres instituciones participaron en la recolección de material vegetal con los aguaruna; la Universidad de Washington y la UPCH con fines biológicos, y el museo para hacer un inventario de la biodiversidad peruana. Con base en algunos contactos previos con la corporación Monsanto con sede en San Luis (Missouri), y para cumplir con el programa del ICBG que "promovía” la colaboración del sector privado, la Universidad de Washington aseguró la participación de G. D. Searle \& Co., en ese entonces la división farmacéutica de Monsanto.

De acuerdo con Lewis (entrevista, 2000), la Organización Central de Comunidades Aguarunas del Alto Marañón (Occaam) fue 


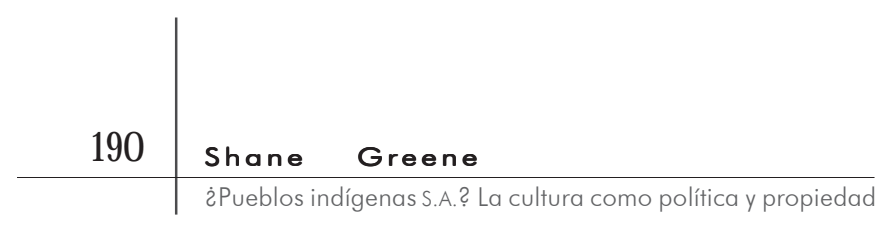

considerada inicialmente como un socio indígena potencial en la solicitud original de la beca del ICBG, pero una vez otorgada el equipo del ICBG comenzó negociaciones con el Consejo Aguaruna Huambisa, una organización indígena históricamente mucho más importante en la región. Lewis (entrevista, 2000) dijo que el NIH lo remitió al Consejo y a su internacionalmente famoso fundador y presidente, Evaristo Nugkuag, pero el actual director del ICBG, Joshua Rosenthal (comunicación personal) controvierte esa versión. En todo caso, el Consejo era, aparentemente, el actor institucional más sobresaliente entre los aguaruna. Hasta épocas recientes, se presumía que representaba a una alta proporción de la población aguaruna, y, sin duda, tiene una historia más prestigiosa que las organizaciones aguaruna más pequeñas y menos visibles. Aún más: la participación de Nugkuag en las organizaciones indígenas locales, nacionales e internacionales, le había dado bastante experiencia con respecto al "networking" internacional, y había ganado varios premios prestigiosos. De todos modos, su fama no estaba exenta de controversia en la agitada política de la representación indígena ${ }^{4}$.

4. En 1986 le fue otorgado el premio Right Livelihood (Nobel alternativo), y en 1991 el premio ambiental Goldman (Goldman Environmental Prize), en reconocimiento a su liderazgo de la Asociación de Desarrollo Interétnica de la Selva Peruana (Aidesep) y la Coordinadora de Organizaciones Indígenas de la Cuenca Amazónica (Coica), y por su trabajo en el área de los derechos indígenas y la conservación ambiental. Aun cuando es claro que es un líder efectivo y carismático, las organizaciones indígenas amazónicas que compiten entre sí por el apoyo de sus miembros han cuestionado hasta dónde representa a los pueblos amazónicos (Smith, 1996).

En abril de 1994, el equipo del ICBG firmó una carta de intención muy sencilla para colaborar con el Consejo Aguaruna Huambisa, en la que se prometía un pago anual por la recolección de plantas, y, en términos más o menos vagos, una parte de las regalías futuras. Una vez asegurado este acuerdo preliminar con el Consejo, los investigadores de la Universidad de Washington volvieron a Estados Unidos y formalizaron los términos en los que iba a participar Searle, mediante un convenio de opción de licencia que hacía a la Universidad de Washington responsable de la entrega de los pagos anuales al Consejo y de cualquier regalía futura que debiera ser repartida entre los cuatro socios. De acuerdo con los términos de este convenio y la carta de intención firmada con el Consejo, la Universidad de Washington se convirtió esencialmente en el intermediario legal entre los intereses farmacéuticos de Estados Unidos y todos los socios peruanos (véase la figura 1 ). 


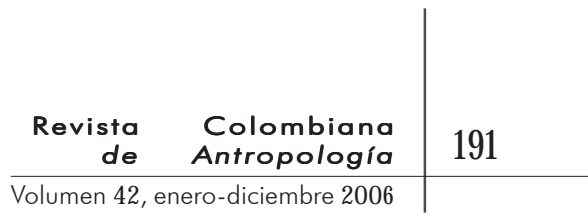

FIGURA 1

ESTRUCTURA DEL CONVENIO EN LA PRIMERA RONDA DE NEGOCIACIONES ICBG-AGUARUNA

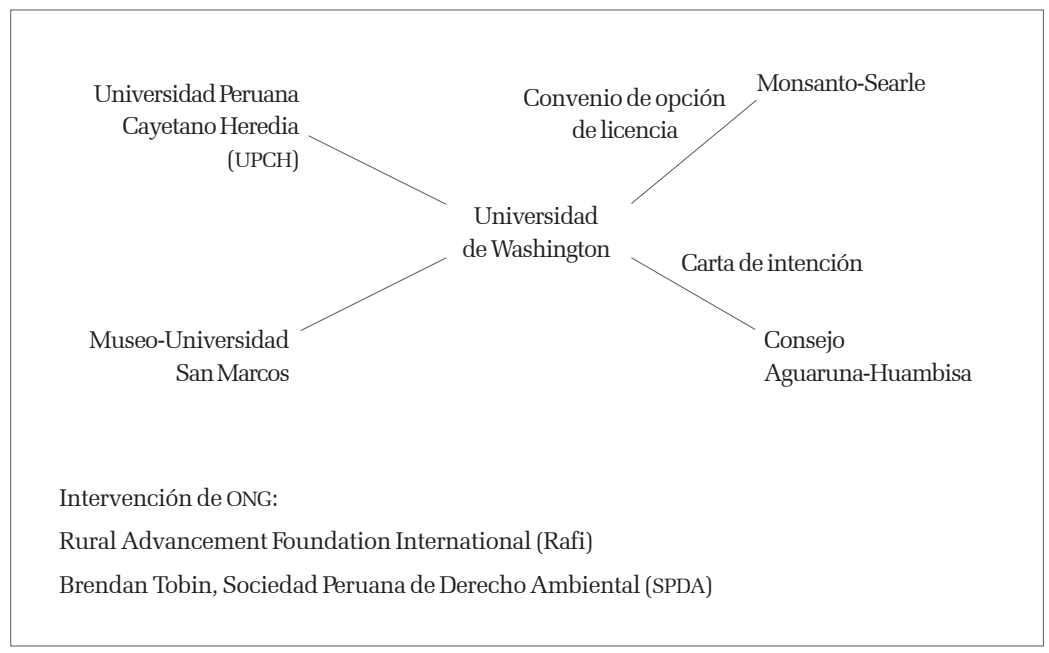

Cuando el Consejo Aguaruna Huambisa supo del convenio que acordaron por separado la Universidad de Washington y Searle, empezó a demorar la investigación y a reclamar más información acerca de su contenido. Como dice Nugkuag, "ellos [el equipo del ICBG] no fueron muy claros. Las utilidades [por ejemplo, el esquema de regalías futuras], se establecieron entre Monsanto y la Universidad de Washington y no se incluyeron en ese convenio. Por tanto, nuestro reclamo [a participar en estas ganancias] es en vano" (entrevista, 2000). Una vez expresadas sus reservas acerca de los beneficios potenciales en el futuro, y del convenio hecho por aparte, el Consejo consultó esto con una ONG estadounidense, la Rural Advancement Foundation Internacional (Rafi: Fundación para el Avance Rural), que trabaja como organismo de control en lo que respecta a actividades de bioprospección ${ }^{5}$. Mediante los contactos del Consejo con la Rafi, obtuvieron una copia del convenio de licencia (Evaristo Nugkuag, entrevista, 2000). La Rafi publicó las tasas de pago de regalías en la página web y acusó a Searle y al equipo del ICBG de "biopiratería", con la intención de explotar el conocimiento aguaruna a favor de los intereses corporativos (Rafi, 1994). A mediados de 1994, Brendan Tobin, abogado irlandés al que

5 Desde entonces, la Rafi cambió su nombre por ETC Group (véase, www.etcgroup.org). 


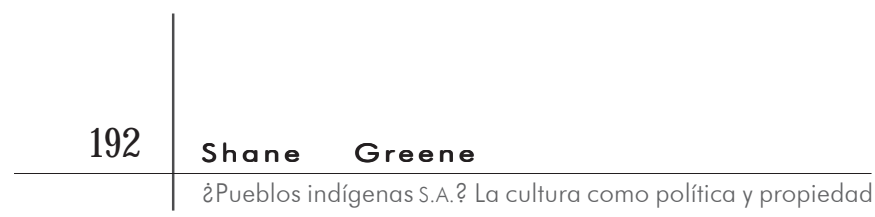

se le había otorgado la ciudadanía peruana y que trabajaba para una ONG llamada la Sociedad Peruana de Derecho Ambiental (SPDA), recibió una copia del convenio y solicitó una copia de la carta de intención al Consejo (comunicación personal, Brendan Tobin). Tobin presentó su objeción debido a las inconsistencias legales entre la carta de intención y el convenio, criticó la tasa de regalías, por ser muy baja, y determinó que la investigación del ICBG-Searle "estaba ligada directamente con la promoción de los intereses económicos y de desarrollo de la industria estadounidense" (1994: 17).

Así pues, la idea que al Consejo le habían ofrecido unos beneficios exiguos surgió al consultar a dos ONG. De hecho, ya se había firmado la carta de intención y aceptado diez mil dólares como parte de un pago anual especificado en la carta, como compensación por la colecta de material (Lambrecht, 1988). Las opiniones de las dos ONG reclamaban negociaciones más directas y transparentes entre Searle y los aguaruna (véanse, Tobin, 1994; Rafi, 1995). Tanto el polémico ataque de la Rafi al programa del ICBG como el análisis legal de Tobin asumían que la bioprospección utilizando el conocimiento tradicional de los aguaruna era de gran importancia para Searle; por tanto, las fallas en la estructura del convenio se consideraban un intento por despojarlos de un conocimiento tradicional de mucho valor.

Aún con las preocupaciones del Consejo sin resolver, a finales de 1994 el equipo del ICBG comenzó su trabajo de campo. Es imposible verificar exactamente cómo y dónde recolectó plantas durante este periodo conflictivo. Lewis (entrevista, 2000) afirma que las colectas se hicieron conjuntamente con funcionarios locales del Ministerio de Agricultura, y en su gran mayoría sin informantes indígenas, en las colinas que rodean un asentamiento no-indígena denominado Imazita. Nugkuag (entrevista, 2000), dice que los investigadores del ICBG cometieron un error garrafal al escoger trabajar con el Ministerio de Agricultura, y que "sin tener la autorización para entrar en las comunidades, con los jefes de las comunidades se adentraron a recolectar orquídeas. Recolectaron otros tipos de plantas medicinales de manera discreta, se podría decir”. Lewis (comunicación personal) niega esto último tajantemente; dice que de las cerca de trescientas muestras recolectadas en ese periodo, sólo unas diez las recogieron informantes aguaruna provenientes de la comunidad principal de la Occaam, que había autorizado a los investigadores. 


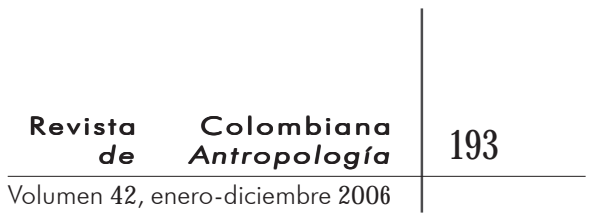

A principios de 1995 a medida que crecía la desconfianza en las actividades del equipo del ICBG, el Consejo se retiró del proyecto ICBG. El equipo del ICBG volvió al área aguaruna para hablar con los líderes de la Occaam, con la esperanza de encontrar un socio indígena receptivo a la investigación. Los líderes de la Occaam apoyaron el proyecto y se involucraron rápidamente en el programa del ICBG, mediante un acuerdo por separado, mucho más elaborado que el de la carta de intención original. Al conocer del nuevo acuerdo, el Consejo envió una carta bastante fuerte a funcionarios del NIH y de la Universidad de Washington, firmada por varios jefes de comunidades aguaruna y líderes del Consejo, en la que protestaba contra las actividades del ICBG. Este hizo pública la carta por medio de sus contactos en la Rafi, quienes la tradujeron de inmediato y publicaron apartes en su portal (Rafi, 1995). La carta alegaba, entre otras cosas, que la Universidad de Washington no le había proporcionado al Consejo información adecuada sobre el acuerdo de licencia y había entrado al territorio aguaruna sin autorización, por lo que reclamaba, enérgicamente, la terminación del proyecto. De manera significativa, insinuaba también que la Occaam no existía, refiriéndose a ella como "el grupo fantasma". Sin embargo, los esfuerzos organizativos de la Occaam -iniciados hacia 1975- habían comenzado antes que los del Consejo -iniciados alrededor de 1977-, y desde el principio la relación entre ambas organizaciones había sido conflictiva.

En sus publicaciones en la red, la Rafi muestra al Consejo Aguaruna Huambisa como el único órgano representativo del pueblo aguaruna. Su informe sobre el conflicto entre el ICBG y el Consejo dice que "sin haber consultado con o recibir la aprobación de los indígenas, los investigadores de la Universidad de Washington decidieron unilateralmente iniciar la colecta de muestras y de material etnográfico -que debía ser entregada al gigante químico Monsanto- en remotas comunidades nativas del noreste del Perú" (Rafi, 1995 5). No mencionan las relaciones del ICBG con la Occaam ni el acuerdo suscrito con ellos. En cambio, presentan a "los aguaruna” como una masa homogénea única, representada sin problema alguno por el Consejo, una representación que no refleja para nada la realidad aguaruna contemporánea o tradicional. Es claro que la Occaam era invisible internacionalmente y no tenía contactos con ONG transnacionales, mientras que el Consejo tenía ambas. Pero las cosas estaban a punto de cambiar. 


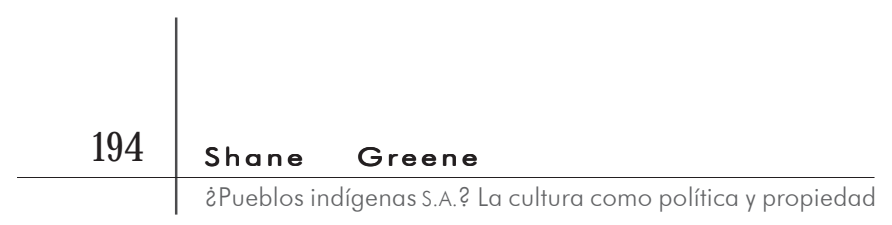

Aun cuando el deseo de sacar el proyecto de territorio aguaruna no se materializó, la carta de protesta del Consejo y su traducción/publicación por parte de la Rafi, para una audiencia angloparlante activista, resultó ser un arma bastante útil. Los funcionarios del programa del ICBG en el NIH tomaron en serio la protesta, hicieron su propia investigación e insistieron en que los

6. Hay que anotar que las trescientas muestras recolectadas durante el periodo de tiempo en disputa no fueron devueltas a los aguaruna sino al Ministerio de Agricultura (Tobin, 1999a). Sin importar si las acusaciones hechas en su contra por el Consejo son verdaderas o falsas, sobre lo que no puedo opinar ya que no estuve presente, Lewis reconoce ahora su "inocencia política" (véase, Lambrecht, 1998) en lo que se refiere a la complejidad de la política y estructura organizativa aguaruna. investigadores devolvieran todas las muestras recolectadas en Perú durante el periodo en cuestión. El NIH insistió también en que si los investigadores del ICBG querían continuar con la beca debían dejar en claro los términos de aceptación del proyecto con representantes legítimos de las comunidades aguaruna ${ }^{6}$. Por tanto, era necesario iniciar una nueva ronda de negociaciones.

\section{SEgundo Asalto}

E N RESPUESTA A LA CARTA DE PROTESTA DEL CONSEJO, Y CON LA ESPEranza de salvar el proyecto, un aguaruna llamado Ricardo Apanú -involucrado con la Occaam y quien más tarde se convertiría en el coordinador en campo del ICBG- comenzó a organizar la defensa de las actividades del equipo del ICBG, con el apoyo de otras dos organizaciones aguaruna, la Federación de Comunidades Nativas Aguarunas del Río Nieva (Feconarín) y la Federación Aguaruna del Río Domingusa (Fad). En abril de 1995 , las tres organizaciones firmaron, sellaron y enviaron una respuesta escrita a todos quienes recibieron la carta de protesta del Consejo. Este "memorial" dejaba en claro que los investigadores del ICBG habían trabajado de manera apropiada con los líderes de la Occaam y sus comunidades afiliadas. Además, criticaba duramente a Evaristo Nugkuag, y rechazba categóricamente su capacidad para representar al pueblo aguaruna -"desconocer" su representatividad-e, incluso, cuestionaba la autenticidad de la carta de protesta.

En otro esfuerzo por cambiar las posiciones políticas a su favor, las tres organizaciones locales aguaruna pusieron a los 


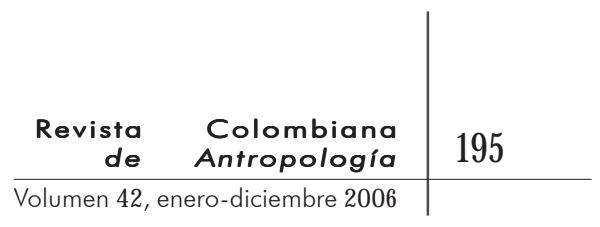

investigadores del ICBG en contacto con un actor nacional: la Confederación de Nacionalidades Amazónicas del Perú (Conap). Con base en Lima, la Conap -cuyo presidente es de origen aguaruna- es una confederación indígena multiétnica del Amazonas, a la que estan afiliadas la Occaam, la Feconarín y la Fad. Las discusiones iniciales culminaron en una reunión en diciembre de 1995en Santa María de Nieva, un pequeño puerto fluvial en territorio aguaruna. Ante la ausencia del Consejo Aguaruna Huambisa y de otras organizaciones aguaruna, la Conap convocó a una reunión con algunos líderes comunitarios y de organizaciones, entre ellos líderes y delegados de las tres organizaciones interesadas, de otras dos organizaciones aguaruna, la Organización de Desarrollo de las Comunidades Fronterizas del Cenepa (Odecofroc) y la Organización Aguaruna del Alto Mayo (Oaam), y a una organización huambisa, la Federación de Comunidades Nativas del Río Santiago (Feconarsa).

En la reunión estuvieron presentes también los investigadores del ICBG, Brendan Tobin de la SPDA, y un representante de Searle, estableciendo por primera vez contacto directo entre la compañía farmacéutica y los representantes aguaruna. Después de un largo debate sobre el proyecto del ICBG y de una extensa discusión sobre asuntos internos, la Occaam, la Feconarín y la Fad aceptaron la investigación del ICBG en sus comunidades afiliadas, se apoyaron en la Conap, su asociado nacional y, extraoficialmente, crearon un consorcio de organizaciones aguaruna al que me referiré de ahora en adelante como Conap y afiliados. Aun cuando al principio las comunidades de la Occaam estaban localizadas fuera del área de investigación, fueron incluidas luego en el acuerdo del ICBG, convirtiéndose así en el cuarto socio aguaruna de la Conap y afiliados ${ }^{7}$. Un punto importante discutido en la reunión de 1995 fue la posible inclusión de la Odecofroc y la Feconarsa. Los

7. Es claro que la aceptación por parte de la Conap y afiliados no significó la aceptación automática por parte de todas las comunidades aguaruna formalmente afiliadas a esas organizaciones. En muchos casos, comunidades individuales cuestionaron la autoridad de la Conap y afiliados para aceptar el proyecto en su nombre, y se rehusaron a permitir que los investigadores del ICBG trabajaran en sus territorios, a pesar de estar afiliados a una de las organizaciones participantes. Aun cuando no hay suficiente espacio para documentar las disputas locales internas, es importante mencionarlas, ya que incluso la aparente asociación de estas organizaciones provocó una serie de debates, discusiones y desacuerdos internos entre los líderes de las comunidades aguaruna. líderes de la Conap explicaron que mientras las otras organizaciones se habían registrado como asociaciones civiles sin ánimo de lucro, estas dos care- 


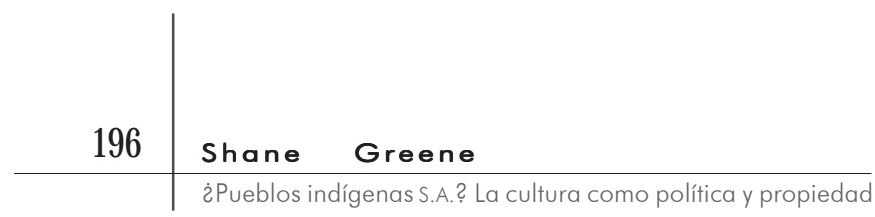

cían de reconocimiento formal en el sistema legal peruano y, además, antes habían mantenido una afiliación estrecha al Consejo Aguaruna Huambisa. Tanto el presidente de la Odecofroc como un delegado de la Feconarsa aprovecharon la ocasión para criticar al Consejo. La al parecer eterna asociación entre el Consejo y su alguna vez famoso fundador y líder visionario convirtieron el evento en una oportunidad para juzgar las actuaciones de Evaristo Nugkuag, quien ya se había convertido en blanco fácil dentro del juego de culpabilidades aguaruna. De hecho, durante esa reunión el fundador y primer presidente de Odecofroc anunció que su organización terminaría pronto su asociación con el Consejo. Aun cuando ambas organizaciones lograron convertirse eventualmente en asociaciones sin ánimo de lucro y

8. La información que presento sobre esta reunión entre las organizaciones aguaruna y los investigadores del ICBG, la SPDA y Searle fue tomada de las notas que conforman un apéndice al acuerdo de recolección biológica firmado en 1996. Es irónico que a pesar de la ausencia de los entonces líderes activos del Consejo Aguaruna Huambisa, su secretario, Santiago Manuig, había sido presidente del Consejo (1989-1993). Ya que él también había desarrollado una relación conflictiva con Nugkuag, usó la reunión para cuestionar las actividades de su sucesor. finalizaron su relación con el Consejo, ninguna se convirtió en miembro de la Conap y afiliados o recibió algún tipo de beneficio de la investigación ${ }^{8}$.

Como resultado de esta reunión histórica, tres personas fueron designadas para negociar los detalles del contrato mediante el cual la Conap y afiliados aceptaban el acuerdo con los investigadores del ICBG y Searle: César Sarasara, el presidente aguaruna de la Conap, Mercedes Manríquez, una abogada limeña de la Conap, y Brendan Tobin, del SPDA. Después de varias discusiones y borradores del acuerdo, en mayo de 1996 un equipo que incluía a Sarasara y a los dos abogados viajó a San Luis (Missouri) a ultimar personalmente los detalles del contrato con Searle y sus abogados. En la figura 2 se puede apreciar la estructura del acuerdo.

En este segundo asalto, la Conap y afiliados, representados por Sarasara y los dos abogados, negociaron el contrato directamente con Searle, sin que las relaciones estuviesen mediadas ya por la Universidad de Washington. Esto fue un logro signifcativo para los pueblos indígenas involucrados, que lo reconocen como tal. Es, por cierto, una de las primeras instancias en las que un grupo indígena ha representado sus propios intereses -si bien mediados por expertos legales no indígenas- con una importante compañía faramacéutica en lo que respecta a la potencial 
FIGURA 2

ESTRUCTURA DEL CONVENIO EN LA PRIMERA RONDA DE NEGOCIACIONES ICBG-AGUARUNA

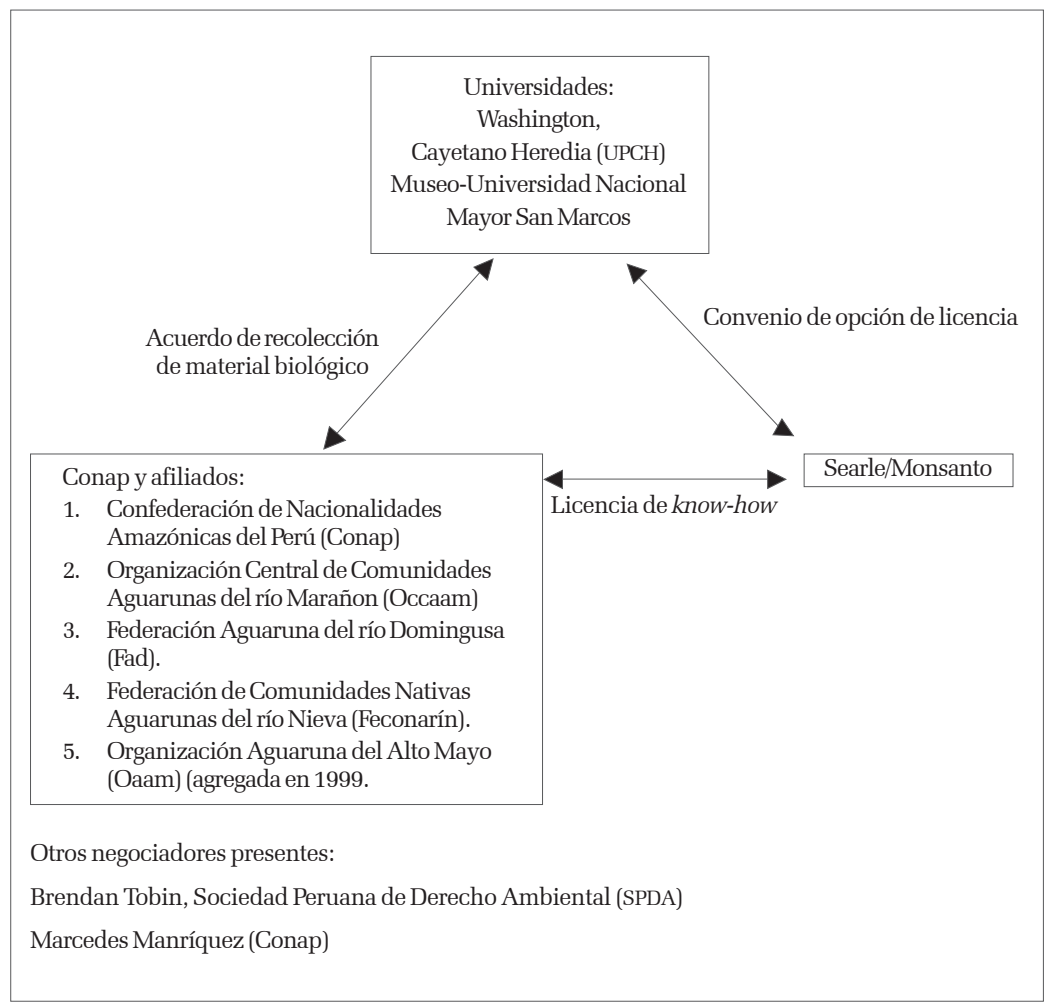

comercialización de su conocimiento tradicional. Esta ronda de negociaciones tuvo como resultado un esquema de regalías y pagos anuales distinto, y, más significativo aún, un acuerdo de licen-

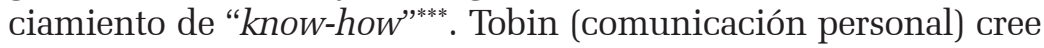
que el licenciamiento del know-how es un paso verdaderamente novedoso en el derecho contractual, ya que por primera vez le otorga a un grupo de pueblos indígenas el control y la propiedad sobre su conocimiento tradicional. En términos legales, los representantes de la Conap y afiliados, que eran los únicos socios indígenas firmantes, le dieron licencia a Searle, directamente, sobre el conocimiento médico tradicional, concebi*** El know-how, o saber hacer, es un componente legal muy importante dentro de los derechos de propiedad industrial e intelectual, ya que incluye el dominio sobre los conocimientos técnicos secretos necesarios y do como un know-how colecsu sustracción del dominio público. Nota del traductor. 


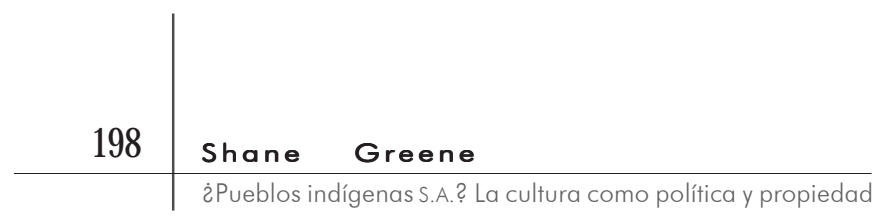

tivo de todos los aguaruna por un periodo inicial de cuatro años (véanse, Tobin, 1999; s. f.). La distribución de los pagos anuales se reformuló y se dividió en dos: un "pago por recolección” de muestras vegetales, y "pagos por licenciamineto" del know-how médico aguaruna. La licencia de know-how estipuló también que se debían hacer dos pagos anticipados no-reembolsables de regalías a la Conap y afiliados, siempre y cuando Searle llegara a dos etapas avanzadas de aprobación de un nuevo medicamento basado en investigaciones realizadas por el ICBG.

Además del licenciamiento del know-how, la Conap y afiliados firmaron un acuerdo con los investigadores del ICBG sobre la recolección de material biológico, especificando los términos y las condiciones de las colectas en campo. Este acuerdo incluía un artículo en el que se "aseguraba la reparticióon justa y equitativa de beneficios entre el pueblo aguaruna" (artículo 301). Así pues, el acuerdo estaba abierto a la participación de otras comunidades aguaruna, con el único requisito que solicitaran su inclusión mediante la afiliación a una organización aguaruna existente, y a otras organizaciones aguaruna, siempre y cuando fuesen aprobadas por la Conap y afiliados en una asamblea y diálogo tradicional llamado el Ipaamamu, que se ha vuelto una parte central de la estrategia de la Conap para tratar con las circunscripciones locales (artículo $7^{\circ}$ ). Esta medida de inclusión y promoción de la repartición equitativa es importante porque, de hecho, el consorcio agurauna representado por la Conap y afiliados sólo da cuenta de la mitad de la población aguaruna (Tobin, 1999a). La no exclusividad de los contratos refleja el hecho que los derechos de propiedad reclamados sobre el knowhow asociado a la medicina tradicional indígena son colectivos y están cobijados bajo el nombre "el pueblo aguaruna", categoría que ha sido usada de manera consistente en los acuerdos con el ICBG.

La definición de "pueblo aguruna" utilizada en el acuerdo que regula la colecta de material biológico los identifica como aquellos "que viven en el área de recolección”, mientras que el "área de recolección" se define como las áreas "habitadas por miembros de las organizaciones colaboradoras" (artículo $1^{\circ}$ ). "Organizaciones colaboradoras" (artículo 106) hace referencia a lo que he llamado "Conap y afiliados", con el fin de reflejar la naturaleza contractual de este intento por incorporar al subgrupo 


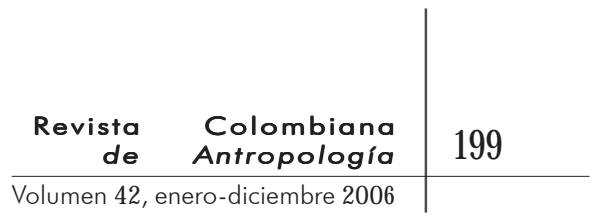

específico de organizaciones aguaruna que firmaron el acuerdo. Esta definición excluye a los aguruanas que son miembros de otras organizaciones o que viven en áreas no organizadas que hayan escogido no ser parte de la Conap y afiliados, y que probablemente no saben que existe esa posibilidad. Irónicamente, estas personas que no participan, incluido el Consejo Aguaruna Huambisa, constituyen una clara mayoría aguaruna. Aún más: lo que quedó en claro en los acuerdos de la segunda ronda de negociaciones es que todos los dineros son y continuarán siendo canalizados por la Conap y afiliados (artículo 301). Para resumir, los acuerdos con el ICBG, si bien pretenden no ser exclusivos entre sus socios indígenas, de hecho tienen el efecto contrario. El acuerdo legal se mueve hacia la legitimación contractual y financiera de la Conap y afiliados como representantes del "pueblo aguaruna"9.

En esencia, entonces, se deshizo la exclusividad arbitraria -relativa- y el exceso de simplificación que implicó la maniobra de la Rafi para legitimar al Consejo Aguaruna Huambisa en protesta por la bioprospección en el primer asalto,

9. A pesar de que el estado pervano firmó el Convenio sobre diversidad biológica y que dos importantes universidades pervanas - una pública y una privada- estaban participando, su ausencia en las dos rondas de negociaciones ICBG-aguaruna fue notoria, con excepción de los requisitos de licencia exigidos por el Ministerio de Agricultura (Tobin, s. f.: 6-7). Es interesante, sin embargo, que basándose en su experiencia en este caso, el estado ha empezado a implementar una aproximación contraria. Los acuerdos entre los aguaruna y el ICBG y Searle han sido utilizados como modelo para la propuesta legislativa sobre el acceso a los recursos genéticos y el conocimiento tradicional en los que el estado tendrá un papel mucho más intervencionista (Tobin, s. f.: 31-32)

para verse duplicada a otro nivel, por la contramaniobra del ICBG y de Searle para legitimar a la Conap y afiliados como apoyo para el proyecto en el segundo asalto. La principal diferencia fueron sus agendas encontradas y las organizaciones indígenas que escogieron apoyar como la legítima "voz" del "pueblo aguaruna".

\section{Los resultados: pocas posibilidades de éxito y grandes expectativas}

IJ NA VEZ FIRMADOS LOS MÚLTIPLES ACUERDOS, EL PROYECTO ICBGaguaruna empezó en $\mathbf{1 9 9 6} \mathrm{con}$ el incicio de nuevas colectas, y a lo largo de los cuatro años siguientes trabajó con comunidades afiliadas a la Occaam, la Fad, la Feconarin y la Oaam. 


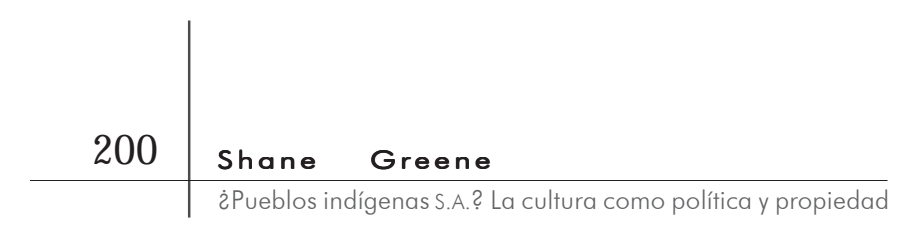

Los investigadores visitaron veintidós comunidades aguaruna y recolectaron aproximadamente 3500 extractos medicinales ${ }^{10}$.

10. 3500 es una cantidad engañosa, en tanto que, de acuerdo con Lewis (comunicación personal), muchos de estos extractos son duplicados de una misma planta. Es importante anotar también que se colectaron otras plantas que no son medicinales -algunas de las que no fueron identificadas por los aguaruna-, para un inventario de biodiversidad, cuyas muestras se enviaron al museo de San Marcos en Lima y a los Missouri Botanical Gardens, y no estuvieron disponibles en el momento de hacer el tamizaje. Por tanto, el total de plantas recolectadas se acerca a 4.800 (Lewis, entrevista, 2000).

En términos de la equidad global en biodiversidad y de los objetivos del Convenio sobre diversidad biológica, los beneficios para el país huésped fueron significativos. De acuerdo con Lewis (entrevista, 2000) el valor de los fondos de investigación, de los recursos y la tecnología llevados al Perú por el proyecto alcanzó un total de un millón de dólares. La mayor parte de estos beneficios fue posible gracias a los fondos de becas públicas, y se canalizaron por medio de dos universidades peruanas, dando oportunidad de entrenamiento e investigación a profesores y estudiantes peruanos (Lewis et al., 1998: 81). El proyecto del ICBG ofreció también oportunidades de entrenamiento ambiental y de educación universitaria a los aguaruna involucrados (Lewis, entrevista, 2000). Dos aguaruna quedaron tan bien entrenados en métodos botánicos y de clasificación científica que eventualmente terminaron dirigiendo sus propias colectas en campo (Lewis et al., 1999. 81). La Conap y afiliados utilizaron una parte de los dineros provenientes de la licencia anual de know-how y de las recolecciones pagadas por Searle para sufragar sus propias necesidades organizativas, y distribuyeron el resto entre sus comunidades afiliadas mediante préstamos pequeños, becas para estudiantes aguaruna y pagos individuales para los informantes en campo que trabajaron con los investigadores del ICBG en la identificación de plantas medicinales.

Uno de los efectos más significativos del ICBG fue la cantidad de capital simbólico y político que le dejó a la Conap y a su presidente, César Sarasara. Cuando la visité por primera vez en 1997, la Conap era poco más que César Sarasara, un par de escritorios, un teléfono y una máquina de escribir en una pequeña oficina en Lima, y constantemente debía pedir préstamos para pagar el arriendo y los servicios públicos. Unos años más tarde ya tenía personal en nómina, patrocinaba eventos y tenía los equipos que tiene cualquier ONG: computadores, fax, portal en internet, etcétera. El título en administración de empresas y su origen aguaruna hacen 


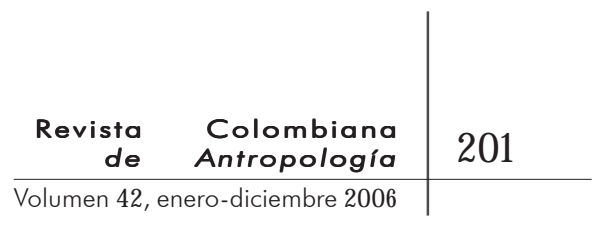

de Sarasara un líder llamativo y un negociador multicultural sagaz, por lo que con frecuencia es invitado a hablar en el circuito global de los representantes indígenas y solicitado por los medios. Además, ganó un premio de la Sociedad Internacional de Etnobiología y fue coautor de un artículo científico, todo lo cual está relacionado con el proyecto ${ }^{11}$.

El surgimiento de la Conap y afiliados contrasta con la caída del Consejo Aguaruna Huambisa, cuyo éxito momentáneo al cuestionar la legitimidad de las investigaciones del ICBG por medio de la Rafi se vió opacado pronto, por la renegociación exitosa del proyecto realizada por la Conap y afiliados. En el Perú se ha vuelto común que actores externos y los mismos indígenas cuestionen la legitimidad del Consejo, en parte por sus fuertes vínculos con su antiguo y controvertido líder. Uno de los fundadores del Consejo, Pancho Juwau (entrevista, 2000), comentaba cínicamente que cuando las personas mencionan el Consejo piensan que "Eso apesta desde lejos"12.

Otro resultado importante y aleccionador de la experiencia ICBG-aguaruna es el claro choque entre las posibilidades de éxito real y las expectativas generadas en el curso de las negociaciones (Greene, 2002). El intento de la Conap y afiliados de privatizar el conocimiento médico tradicional ha tenido como consecuencia generar altas expectativas locales de recibir sumas considerables de dinero. Generar expectativas sobre ganancias económicas sustanciales a largo plazo fue parte esencial de la estrategia utilizada para persuadir a las comunidades locales de que aceptaran el proyecto. El anterior presidente de la Fad informaba, por ejemplo, que los aguaruna del río Domingusa, siguiendo la gran tradición milenarista, esperaban que en el año 2000 les llegaran millones de dólares, apenas cuatro años después de iniciar la recolección de muestras. En las reuniones de la

11 Sarasara se ha relacionado con la prensa en varias ocasiones (véanse, Lambrecht, 1998; Chatteriee, 1997); la Sociedad Internacional de Etnobiología le otorgó el premio José Guallart en su primera edición (Lewis, comunicación personal) y es coautor en Lewis et al. (1999.

12. La historia detallada de las organizaciones indígenas es mejor tratarla en otro escrito. Aun cuando la intención original del Consejo era representar varias cuencas -las de los ríos Marañón, Chiriaco, Nieva Santiago, Cenepa, Domingusa-y manejaba muchos proyectos, la Occaam en gran parte se encontraba aislada. La Feconarín y la Fad fueron fundadas alrededor de 1990 por algunos aguaruna desilusionados con el Consejo, y a mediados de la década de 1990 la Odefroc y la Feconarsa aparecieron en la misma área haciendo críticas similares al Consejo. Los actuales líderes del Consejo son muy conscientes de la fragmentación y pérdida de prestigio de la organización. Los últimos dos o tres presidentes han tratado de tomar medidas para solucionar los que llaman la "crisis" del Consejo. Por lo pronto, los resultados son poco alentadores. 


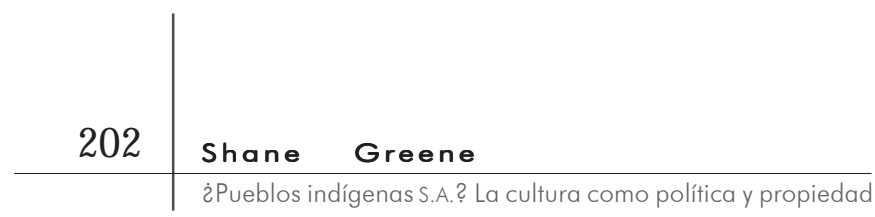

Conap con las comunidades afiliadas a Oaam vi varias veces cómo los líderes creaban grandes expectativas al hablar de la llegada de millones de dólares, como si estuviesen garantizados. El proceso de reconocer que estas expectativas eran exageradas ha comenzado a manifestarse en forma de resentimiento hacia los líderes de la Conap, a quienes se les responsabiliza.

Desde el comienzo, Searle empleó un proceso de tamizaje utilizando maquinaria de alta capacidad, mediante la que se examinaban muestras de plantas para determinar su bioactividad en contra de ciertas enfermedades que la compañía había identificado de antemano con la esperanza de producir indicios interesantes para futuras investigaciones. En efecto, esta aproximación desconocía la información etnomédica específica recolectada por los investigadores del ICBG, que había suscitado tanta controversia al comienzo ${ }^{13}$. Aún más, los exámenes se limitaban a enfermedades como la diabetes, problemas cardiovasculares o la inflamación, problemas de salud mucho más comunes entre los consumidores de Searle que entre los agua-

13 Algunos podrían sostener, obviamente, que el simple hecho de que las plantas hubieran sido identificadas por los aguaruna como útiles en términos médicos es de por sí una contribución intelectual, algo así como un pretamizaje. En mi opinión, la contribución en este punto se ve limitada a una utilidad abstracta, desprovista de todo contenido contextual, práctico, médico, cultural o social. En general, los etnobotánicos creen que la probabilidad de que una planta identificada por los informantes locales sea útil para la investigación y el desarrollo es mucho más alta si para la investigación se usa como guía información específica y detallada sobre su "utilidad" (véase, Farnsworth, 1990).

14. Véase Lewis et al. (1999) acerca de la división de intereses en la investigación entre Searle, la UPCH y la Universidad de Washington y sus resultados hasta la fecha. runa $^{14}$. En septiembre de 1999, Walter Lewis, de la Universidad de Washington, como vocero de Searle, que no había enviado un representante, anunció que la compañía no había encontrado ningún indicio que valiera la pena investigar y que su intención era no extender la licencia de know-how. Desde el punto de vista económico de Searle, el negocio se había acabado. Que Searle nunca hubiese explorado en realidad el know-how aguaruna no significa que no se haya beneficiado de su participación en el programa del ICBG, cuyo proyecto con los aguaruna aparecía en el informe anual de Monsanto a sus consumidores y accionistas como un esfuerzo importante para conservar el bosque tropical y promocionar la repartición de beneficios de acuerdo con el Convenio sobre diversidad biológica, y exaltaba el conocimiento médico tradicional aguaruna. La cancelación de la 


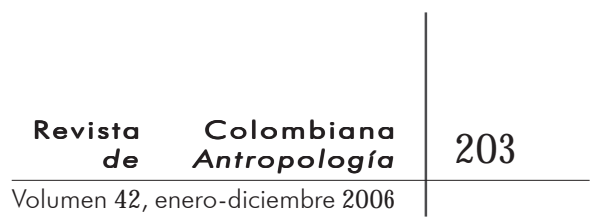

licencia de know-how por parte de Searle fue, obviamente, legítima desde el punto de vista contractual y financiero. Después de todo, los negocios son los negocios ${ }^{15}$.

\section{LA BIOPROSPECCIÓN \\ Y LAS RECLAMACIONES INDÍGENAS \\ DE PROPIEDAD EN UN PANORAMA MÁS AMPLIO}

N LA ACTUALIDAD, LOS ESTUDIOS DE CASO MÁS RECIENTES COMPLICAN - los recuentos más estereotipados de las negociaciones sobre bioprospección, las reclamaciones de los pueblos indígenas sobre su propiedad y las políticas de la representación indígena. Dos de los casos más conocidos involucran demandas contra patentes, una de las cuales, contra una corporación transnacional, tuvo éxito, y otra, menos exitosa, contra un investigador estadounidense. Después de varios años de protestas públicas y de intensos esfuerzos legales por parte de una coalición compuesta por institutos de investigación indígenas y estadounidenses, ONG y organizaciones de agricultores, la Oficina Europea de Patentes revocó la patente a favor de la compañía agroindustrial W. R. Grace (véase, Raghavan, 2000) sobre un compuesto fungicida derivado del árbol neem o nim, como se le conoce en las Américas (Azadirachta indi$c a$, conocido también como neemtree). Vandana Shiva (2000), una de las activistas y científicas indias más vi-

\begin{abstract}
15 Lograr una impresión más completa de los intereses y motivaciones de Searle ha probado ser algo difícil, en especial dados los cambios y adquisiciones. Pude hablar con un ex representante de la firma, que trabajó de cerca con investigadores del ICBG y tuvo contacto con la Conap y afiliados. Prefirió no divulgar información acerca del proyecto, dado que Searle ya no era su empleador. Boletines de prensa de Searle relacionados con el proyecto no estaban disponibles debido a la reestructuración de la compañía. Cuando Monsanto se unió a Pharmaci/Upjohn, Searle fue disuelta y convertida en Pharmacia Corporation. Un empleado de la oficina de medios de Pharmacia me proporcionó algunos artículos del archivo de la compañía que mencionaban el proyecto del ICBG, pero no pudo localizar ningún boletín de prensa distribuido por Searle, y no tenía información acerca de algún contacto dentro de la compañía que conociera el proyecto del ICBG.
\end{abstract} testa, ha demostrado que las propiedades medicinales y de pesticida del neem son conocidas hace milenios por los agricultores de la India, y que el árbol aparece como un símbolo sagrado en las tradiciones sánscrita e islámica. Al sostener que el neem se ha "convertido en un símbolo del conocimiento indígena de la India” nos revela la aparente combinación de la moderna nación 


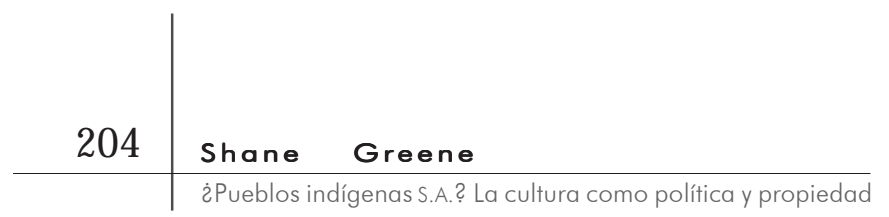

India con los diversos pueblos nativos del subcontinente, antiguos y contemporáneos, y que conocen los múltiples usos del árbol.

En 1999, una coalición formada por varias ONG estadounidenses defensoras de derechos ambientales y la Coordinadora de las Organizaciones Indígenas de la Cuenca Amazónica (Coica), con base en Quito, entablaron una demanda similar ante la Oficina de Patentes de los Estados Unidos (PTO), solicitando la cancelación de la patente sobre una supuesta "nueva" variedad de ayahuasca a un investigador de Estados Unidos. Los pueblos indígenas del Amazonas usan esta liana desde hace siglos para preparar remedios alucinógenos que son centrales a las cosmologías y medicinas tradicionales. La PTO reconoció inicialmente la validez de la petición, pero luego, con base en argumentos legales un tanto dudosos, desestimó la revocatoria de la patente. Los representantes de la Coica consideraron esta decisión "un terrible sacrilegio y asalto a sus valores tradicionales” (Wiser, 2001 13).

Las disputas sobre patentes demuestran que algunos pueblos indígenas e, incluso, voceros y activistas que identifican a naciones enteras del tercer mundo con los pueblos indígenas -como en el caso del nim- se sienten muy insultados por algunos casos de bioprospección politizada. El aparente sacrilegio que se comete y las iniquidades globales históricas que se manifiestan cuando investigadores y compañías foráneas se apropian por medio de patentes de remedios culturalmente sagrados, cumplen un papel crucial en la forma como los pueblos indígenas y los nacionalistas indígenas del tercer mundo conciben sus reclamos sobre propiedades culturales. Por ejemplo, Antonio Jacanamijoy, presidente de la Coica, defendió a nombre de todos los pueblos del Amazonas la posición de su organización, diciendo que la ayahuasca es "una planta sagrada usada para curar nuestras enfermedades, limpiar nuestros espíritus, y predecir nuestro futuro. El ayahuasca le pertenece a todas nuestras comunidades que la usan, y por lo tanto es imposible que pueda ser la propiedad de un solo hombre" (Coica, 2002: 2). En el caso del nim, Shiva (2000) deja en claro que la patente de W. R. Grace sobre el método para emulsionar la semilla del nim es un sacrilegio. Aún más, ella sostiene que este caso de "biopiratería” internacional no sólo no tenía fundamento legal -lo que fue confirmado por la Oficina Europea de Patentes-, sino que, además, aumentó los precios, afectando adversamente a los agricultores tradicionales que dependen de las semillas del nim. 


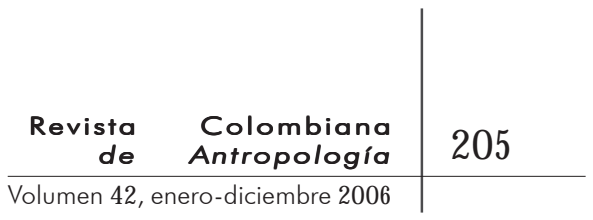

Las negociaciones entre el ICBG y los aguaruna plantean una serie de problemas que han recibido menos atención en la literatura sobre bioprospección y derechos indígenas. En particular, he enfatizado en las políticas que hacen parte de la legitimación y deslegitimación, de algunas formas de representación indígena, las ramificaciones en cuanto a la incorporación de los grupos indígenas al reclamar la cultura como propiedad, y el posible conflicto suscitado por las expectativas asociadas al débil compromiso del sector farmacéutico con la bioprospección. El caso ICBG-aguaruna no es el único que tiene estos problemas: los eventos que llevaron al colapso del proyecto del ICBG con los mayas de Chiapas en 2000 son muy similares (véanse, Brown, 2003, Nigh, 2002). De manera similar, usando una campaña agresiva por medio de internet, la Rafi, con una facción de representantes mayas que se oponía a la investigación, introdujo de nuevo una agenda de biopiratería en las negociaciones, y esta vez los ayudó a detener el proyecto por completo (Rafi, 2000). Intrincadas maniobras políticas que involucraban a representantes indígenas que rivalizaban entre sí, la intervención de ONG y la falta de consenso acerca de quiénes eran los representantes legítimos del pueblo maya, tuvieron un papel importante. En este caso, el socio corporativo era una nueva compañía farmacéutica que recién iniciaba su operaciones y, por ende, tenía un capital tan limitado que la posibilidad de descubrir algún medicamento nuevo era, guardadas proporciones, el equivalente a ganarse la lotería nacional mexicana, según Brent y Elois Ann Berlin, los investigadores principales del proyecto maya (2002: 467). La controversia sobre la representación indígena y la desconfianza de los motivos de los bioprospectores se encontró otra vez con una percepción algo distorsionada de los beneficios económicos potenciales de este tipo de investigaciones sobre el conocimiento de plantas tradicionales.

De las ocho becas de investigación del ICBG otorgadas, es claro que las dos que suscitaron mayor controversia, ICBG-aguaruna e ICBG-maya, requerían de negociaciones directas entre los pueblos indígenas y los bioprospectores, y la intervención de ONG que decían actuar a nombre de o en conjunción con estos pueblos indígenas. Mientras tanto, otros proyectos del ICBG se han desarrollado sin el menor asomo de escándalo en colaboración con universidades, institutos de investigación, y agencias gubernamentales de los países huésped. Cori Hayden (s. f.) le ha 


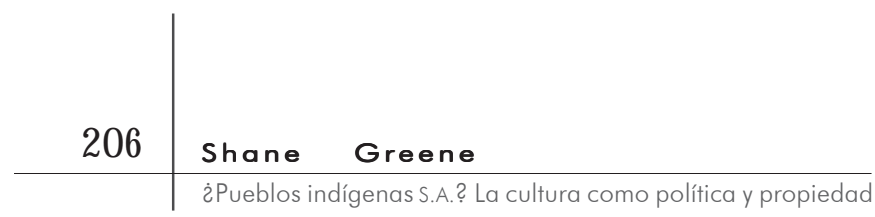

hecho seguimiento a otro proyecto del ICBG de recolección de plantas en Chile, Argentina y México, en el que participan universidades públicas y privadas e institutos de investigación. ICBGLatinoamérica ha recibido fondos del ICBG en dos ocasiones y ha establecido relaciones aparentemente cordiales con sus socios en los países huésped (véase, Timmerman et al., 1999). Hayden le atribuye este éxito aparente a que los investigadores rehusaron, estratégicamente, la pregunta del conocimiento indígena, y evitaron comunidades que se identifiquen como "indígenas" y pudieran reclamar sus propios derechos de propiedad cultural. Al comprar a vendedores locales muestras de plantas en mercados urbanos, los investigadores del ICBG evitan este asunto. Consideran este conocimiento "desindigenizado" sobre las plantas que circula en los mercados urbanos como un bien de consumo, algo que hace parte del dominio público nacional. Así pues, mientras compran plantas a los vendedores locales por un precio "justo", la única obligación de repartir beneficios a largo plazo que deben reconocer es a la nación, representada por las instituciones en las que trabajan sus socios locales de investigación.

El programa ICBG de la Universidad de Illinois en Chicago (UIC) en Laos y Vietnam parece compartir estas dinámicas (Soejarto et al., 1999). Los investigadores de la UIC hacen sus colectas principalmente en parques nacionales -por ejemplo, áreas demarcadas como espacios públicos "nacionales"-, en colaboración contractual con instituciones de investigación públicas y privadas de los países huésped. Para el componente etnobotánico del proyecto, el contacto entre los investigadores extranjeros y las comunidades locales está mediado por instituciones estatales tales como el Comité Nacional de Comunidades Étnicas en Vietnam y el Ministerio de Salud en Laos. Como beneficiarios del proyecto, las instituciones del país huésped hablan por y deben representar los intereses de las comunidades locales en la investigación del ICBG (Soejarto et al., 1999. 107). Los bioprospectores de este tipo se aproximan a las obligaciones de repartición de beneficios principalmente como un problema nacional que debe ser resuelto por instituciones estatales o de otro tipo en el país huésped, que no demuestren incertidumbre acerca de la legitimidad y representación institucionales.

Contrario a la tendencia hacia la hipérbole que presentan usualmente las acusaciones sobre biopiratería global y la desenfrenada explotación del conocimiento indígena, el estado actual de la 


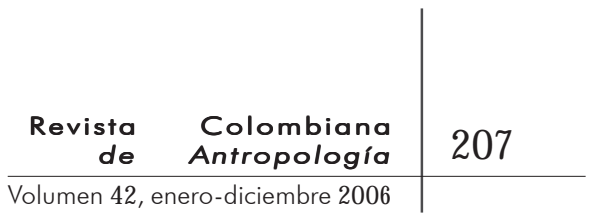

investigación farmacéutica sugiere la necesidad de una comprensión más precisa de las dinámicas en juego. Varios estudiosos han anotado que desde el punto de vista de las inversiones, las compañías farmacéuticas asignan muy poco a la bioprospección de cualquier tipo en comparación con lo que invierten en la investigación sobre drogas sintéticas, modeladas por computador y basadas en ingeniería, que constituye el método preferido de desarrollo de medicamentos (véanse, Albers-Schönberg, 1995, Aylward, 1995, Goering, 1995 10). Los discursos sobre el desarrollo sostenible y la conservación medio ambiental continuarán influenciando sin duda a las compañías farmacéuticas para que consideren las demandas de la esfera pública por un capitalismo ambientalmente responsable. Una política más verde requiere de un capitalismo más moral y más verde. Sin embargo, la idea de un "capitalismo verde" contiene algunas contradicciones inherentes, cuando en realidad parecería que mantener el statu quo capitalista produce mayores rendimientos (Gersh, 1999). El interés por la supervivencia y la acumulación de capital entre los competidores corporativos fácilmente pesa más que el interés en generar un nuevo orden moral y ambiental. Un informe reciente revela que a pesar del énfasis de la industria en el desarrollo de investigación de punta, los productores de medicamentos son entrepreneurs increíblemente poco ingeniosos, que dedican más recursos financieros a la publicidad e imagen corporativas, que aumentan las ventas, que a descubrir nuevos medicamentos (Public Citizen, 2001). El estudio encontró también que una proporción importante -más de la mitadde nuevos productos médicos introducidos entre 1982 y 1991 no eran nuevos medicamentos, sino drogas "yo también," imitaciones levemente modificadas de productos ya existentes.

El débil compromiso con la bioprospección por parte del sector farmacéutico es especialmente obvio en lo que se refiere al tipo de bioprospección que depende directamente del conocimiento indígena. Shaman Pharmaceuticals, una compañía nueva fundada en 1990, fracasó en su intento por descubrir un medicamento lucrativo basado en conocimientos tradicionales sobre plantas; este hecho agrega más pruebas a los resultados de los proyectos ICBG-aguaruna e ICBG-maya. Aun cuando Shaman mantiene una posición coherente con el Convenio sobre diversidad biológica y está dispuesta a implementar mecanismos para repartir las utilidades con comunidades locales que contribuyan con conocimientos médicos tradicionales, tal escenario no existe aún. A pesar de 


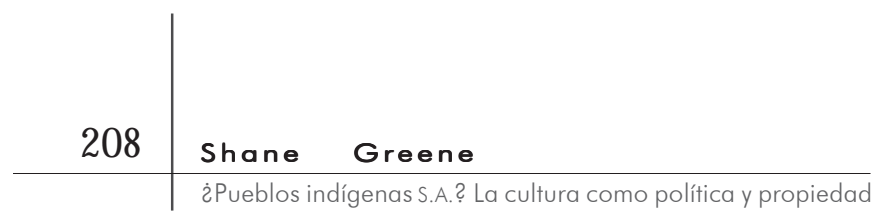

algunos avances significativos con una droga experimental llamada Provir, basada en el remedio tradicional amazónico de la sangre de grado, Shaman se vio forzada a cerrar su división de investigaciones farmacéuticas, y actualmente vende suplementos herbales poco lucrativos, mientras continúa operando con los mismos ideales ambientales y morales aun con una inmensa deuda corporativa (véanse, Brown, 2003 Economist, 1999). Esta es una buena razón para detenerse y reflexionar.

\section{LOS DILEMAS DE LA IN-CORPORACIÓN Y REPRESENTACIÓN INDÍGENAS}

A INCERTIDUMBRE RELATIVA DE LAS COMPAÑÍAS FARMACÉUTICAS CON respecto a la bioprospección y sus preocupaciones acerca de la imagen corporativa en una era medio ambiental, y los esfuerzos cada vez más frecuentes de los grupos indígenas por tratar el conocimiento como propiedad, producen expectativas, presuposiciones y estrategias de negociación muy divergentes. Un panel de expertos externos identificó la creación de expectativas poco realistas con respecto a los supuestos beneficios económicos de la bioprospección en regiones en desarrollo como uno de los mayores peligros en el diseño del programa del ICBG (véase el Report of a Special Panel of Experts on the International Cooperative Biodiversity Group, 1997). Otros autores han anotado que elevar las expectativas en naciones económicamente pobres pero ricas en biodiversidad es un problema general creado por la retórica de la bioprospección (Macilwain, 1998). Yo agregaría que si bien la creación de grandes expectativas puede ser un problema generalizado en la investigación relacionada con la bioprospección, los casos actuales sugieren que estas son más exageradas y politizadas cuando las negociaciones involucran la cuestión de la propiedad cultural y la representación indígena. En efecto, investigadores como Cori Hayden sugieren que al evadir la pregunta sobre el conocimiento indígena y diseñar las actividades de bioprospección en términos de obligaciones con el estado-nación, algunos bioprospectores tratan de evitar, conscientemente, las controversias, confusiones y demandas de biopiratería. Pero, ¿qué hace que los actuales acuerdos de bioprospección con los grupos indígenas produzcan tales desacuerdos? 


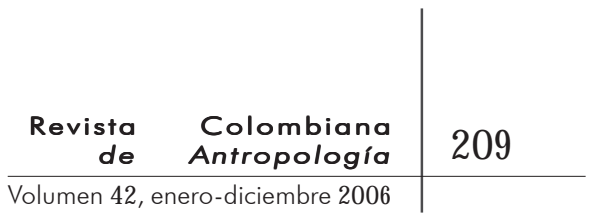

Tal como lo demuestran estos casos, una respuesta es que las sociedades nacionales e internacionales y las comunidades indígenas deben reconocer, legitimar y rutinizar las nuevas políticas globales de representación y movilización en las que muchos grupos indígenas se encuentran envueltos. El debate acerca de quién está hablando por quién en lo que se refiere a los asuntos indígenas continúa creando crisis de representación en las que los líderes, las organizaciones y los voceros indígenas se ven forzados a re/negociar su representatividad, no sólo entre ellos mismos, sino también en relación con los intereses de los actores foráneos que, por lo general, ocupan posiciones con mayor poder, recursos, influencia y prestigio. Aun cuando algunos críticos ven a las ONG internacionales más poderosas como parte del proyecto neoliberal que busca perpetuar la falsa conciencia entre los pueblos marginados sobre su "empoderamiento" (véanse, Petras, 1997; Hardt y Negri, 2000: 36), otros sostienen que en esta era de reducción del estado las ONG son la principal fuerza de democratización, servicio social y desarrollo (véanse, Bebbington et al., 1993, Clark, 1990; Meyer, 1999). En el caso de los pueblos indígenas, las ONG que actúan como aliados y las instituciones indígenas, que comúnmente también son ONG, pueden ejercer y, en efecto, tienen gran influencia contra los intereses privados y estatales. Pero, siendo instituciones burocráticas con sus propios programas políticos y sociales, también es común que estén lejos, geográfica, cultural y lingüísticamente, de los constituyentes locales, lo que puede resultar en una tendencia a simplificar y romantizar las realidades indígenas. Por ejemplo, la imagen tan popular en épocas recientes de los indígenas amazónicos como guardianes del bosque tropical existe hoy día en parte debido a las alianzas establecidas entre ONG ambientales y grupos indígenas en las últimas dos décadas (Conklin y Graham, 1995). De manera similar, un análisis de las negociaciones de bioprospección indica que las ONG que trabajan con los representantes indígenas cumplen un papel determinante a la hora de apoyar las reclamaciones indígenas, mientras que, simultáneamente, crean expectativas exageradas con respecto al potencial económico de las demandas sobre propiedad intelectual, y caen en el juego de miedos asociado con el discurso preponderante de la biopiratería farmacéutica. Por lo general, estas organizaciones proveen recursos y asistencia legal y científica claves, tal como en los casos de las patentes sobre la ayahuasca y el nim; en otros 


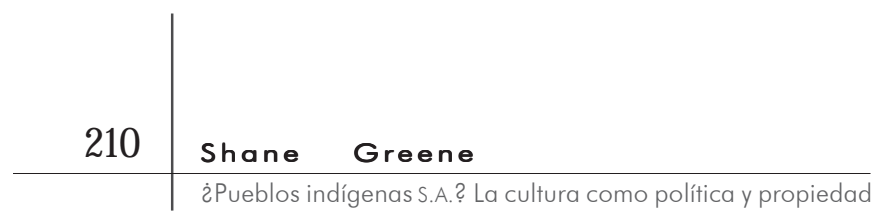

casos, sus actividades, a pesar de tener buenas intenciones, resultan en la legitimación de los grupos indígenas que de manera más clara se ajustan a sus propios objetivos institucionales, políticos y sociales, y a sus formas de auto representación anticorporativa y antibioprospección, sin enfrentar nunca las complejas realidades políticas de las poblaciones locales.

Por más importantes que sean, las ONG son apenas un subgrupo dentro de los múltiples actores que pueden influenciar la negociación y des/legitimación de la representatividad indígena. Los investigadores de toda índole, las organizaciones religiosas, las agencias de financiación internacionales y las corporaciones y burocracias estatales influyen sobre y complican las políticas de representación indígena, de acuerdo con sus propios intereses. La tendencia de las ONG a distorsionar las demandas de representación indígenas a favor de las protestas contra la bioprospección se ven igualadas por las tendencias de los investigadores, los funcionarios estatales y las compañías farmacéuticas de hacer lo mismo a su favor. Ambos lados buscan y tratan de legitimar aliados indígenas de acuerdo con sus objetivos institucionales, políticos y económicos. Más aún, como hemos visto, con frecuencia el desacuerdo y las discusiones internas en los grupos indígenas sobre el problema de la representación le da cierta credibilidad a ambas partes, y muestran también los problemas inherentes de negociar culturas con propiedad colectiva mediante apenas unos selectos brokers indígenas. Debido a la naturaleza colectiva de las demandas que buscan definir la cultura como propiedad, existe una presuposición común a todas las partes: que las colectividades indígenas deben tener una estructura centralizada de autoridades representativas, comparable a la que encontramos en los estados-nación consolidados, con la que los actores externos puedan negociar. Sin embargo, establecer quiénes son los representantes legítimos de una colectividad indígena es frecuentemente un asunto que suscita debates externos e internos. En circunstancias en las que la construcción de instituciones indígenas todavía está en proceso, no debe sorprender que la legitimidad de cualquier organización indígena varíe de acuerdo con las tendencias políticas y el grado de acceso que tengan a actores externos más poderosos.

Esto no hace que, en mi opinión, los pueblos indígenas sean peones inocentes al servicio de jugadores más poderosos, sino que demuestra, en cambio, su participación en redes más amplias 


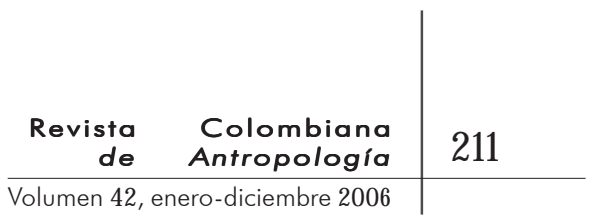

de poder, como estrategas políticos cuyas decisiones repercuten directamente sobre su legitimidad como representantes indígenas. Ganar importantes batallas legales y la inserción exitosa de los programas indígenas en las decisiones de actores e instituciones políticas más poderosas pueden, bajo circunstancias favorables, ser muy efectivas, pero por lo general la "victoria" es relativa. Se deben tener en cuenta también los costos que implica politizar la cultura y tratarla como propiedad. Aun cuando la movilización indígena global es una señal de fuerza significativa para algunos de los pueblos más marginales, las políticas de las autoridades y los voceros indígenas continúan siendo una esfera muy disputada. La representación indígena que apenas está surgiendo se ve apoyada y constreñida, al mismo tiempo, por las alianzas nacionales e internacionales que están identificando continuamente mediadores legítimos entre los intereses externos y las comunidades locales de formas que dependen tanto de sus propias agendas como de las de las colectividades indígenas.

Aun cuando algunos de los casos presentados ilustran principalmente las preocupaciones concernientes al sacrilegio, la representación equívoca y la explotación, otros llevan a considerar las ramificaciones de las expectativas y aspiraciones económicas que nacen a partir de las demandas sobre la propiedad cultural indígena. Algunos han enfatizado en que los reclamos sobre la propiedad cultural, basados en leyes occidentales sobre propiedad intelectual, implican la privatización derivada directamente de los ideales y modelos del mercado (véanse, Brush, 1996, 1999, Coombe, 1998, 1999). Los casos analizados demuestran que las demandas sobre propiedad cultural son utilizadas, de hecho, en contra de los intereses externos del mercado, y también de acuerdo con los intereses internos de los mismos grupos indígenas, que buscan utilizar el mercado para favorecer sus movilizaciones. Los casos del nim y la ayahuasca, por ejemplo, giran alrededor de lo que se percibe como un ataque moral, cultural y económico sobre el derecho que tienen una nación y un pueblo indígena de prohibir que un conocimiento considerado propiedad colectiva se vuelva la propiedad patentada y exclusiva de una corporación o individuo privado. El material que presenté sobre el caso ICBGaguaruna sugiere que se deben tomar en consideración las formas en que las reclamaciones indígenas sobre la propiedad cultural llevan también a estrategias empresariales locales, y que es importante examinar las ramificaciones potenciales de estas 


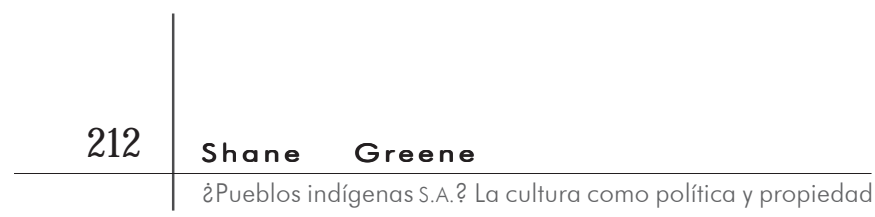

estrategias. Tratar la cultura como propiedad es una estrategia utilizada por los grupos indígenas para adoptar y transformar la lógica de sus contrapartes occidentales, para mercadearse como Pueblos indígenas S. A. y crear una forma de actividad económica políticamente consciente, que en otros contextos ha sido denominada "capitalismo tribal" (véase Rata, citado en Friedman, 1999. 9).

El proyecto ICBG-aguaruna demuestra que la actividad empresarial indígena hace parte también de las demandas sobre la propiedad cultural. La licencia de know-how firmada con Searle es una instancia clara de esto, al igual que la solicitud de una patente de utilidad radicada por investigadores de la Universidad de Washington en 2003(Lewis y Ramani, n. d.). La falta de apoyo corporativo desde el retiro de Searle no ha impedido la investigación etnobotánica de Walter Lewis sobre las muestras de plantas recogidas entre los aguaruna, lo que ha producido importantes indicios en el área de los antimaláricos, que él y sus colegas buscan proteger mediante patente. En la solicitud de patente, los inventores han asignado el mismo porcentaje de propiedad $-25 \%$ a cada uno- a los miembros de los cuatro socios iniciales del ICBG. Uno de los cuatro potenciales propietarios de la patente es la Conap, representante de las federaciones aguaruna locales so-

16. La patente menciona a cada uno de los informantes que identificó las plantas de las que se han podido aislar los compuestos patentados, y a las comunidades aguaruna en las que viven (Walter Lewis, comunicación personal). La decisión de incluir únicamente a la Conap como representante de otras cuatro federaciones aguaruna en la solicitud de la patente, en vez de todas juntas como en el acuerdo de recolección biológica, es curiosa. Como actor nacional, es obvio que la Conap es más estable y conveniente para coordinar estos asuntos. Sin embargo, a diferencia de todas las otras federaciones involucradas, no es una organización exclusivamente aguaruna, sino una confederación interétnica, y otros indígenas amazónicos constituyen la mayoría de los afiliados locales de la Conap: los pueblos shipibo y yanesha son especialmente importantes. Ninguno de ellos tuvo algo que ver con las colectas realizadas por el ICBG, pero como miembros activos de una organización que funciona de manera democrática se podría asumir que tienen tanto derecho sobre la propiedad patentada como las organizaciones aguaruna representadas por la Conap. Parece como si las complejidades de identificar stakeholders, socios contractuales y propietarios de conocimiento indígena no hicieran más que multiplicarse. cios en los acuerdos. De ser otorgada la patente, es probable que la Conap se convierta en una de las primeras instituciones indígenas en el mundo en ser dueña de conocimiento patentado. La probabilidad de que una patente se convierta en utilidades es, claro, bastante baja, pero uno no puede dejar de reconocer los intereses económicos que hay detrás de este tipo de movilización indígena en particu$\operatorname{lar}^{16}$.

Pero, exactamente, ¿qué ocupa un lugar central en las estrategias indígenas de movilización que podemos 


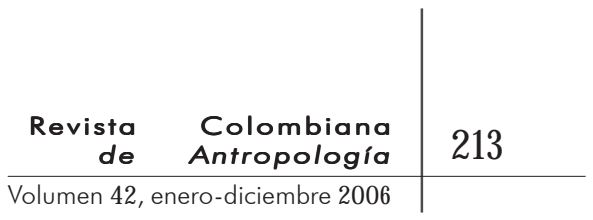

observar, no sólo en las negociaciones sobre bioprospección, sino también en el mercadeo de artesanías tradicionales, música popular y etno y ecoturismo? A fin de cuentas, lo que se representa, discute, negocia y, en algunos casos, vende, es la identidad indígena como tal (véanse Brysk, 2000: capítulo 4; Conklin y Graham, 1995, Friedman, 1999, Sylvain, 2002). Lo que se ha privatizado no es sólo el conocimiento amazónico sobre las plantas, la música andina o los tours en una aldea. A un nivel más básico, las identidades de los grupos indígenas se ven sujetas a estas estrategias, ya que por lo general es el vínculo con una cultura e identidad indígena lo que las hace un bien de consumo atractivo para los consumidores y productores globales.

Privatizar y mercadear partes de su cultura o recursos tradicionales es otra estrategia usada en una política más amplia de autodeterminación, que surge en conexión con la demanda económica del mercado global. Es precisamente mediante esta actividad empresarial indígena que grupos como la Conap y afiliados promueven una movilización específicamente indígena. Ellos dicen que la movilización indígena necesita mucho más que un sólido trasfondo histórico y cultural como parte de las políticas identitarias multiculturales de hoy. Requiere también de viabilidad económica, ya que su supervivencia como movimiento social organizado tiene un vínculo directo con la solvencia financiera de las instituciones fundadas por los grupos indígenas y las comunidades representadas por ellos, en un mundo dominado por las relaciones de mercado. Esta complicada situación hace insostenible cualquier explicación de la incorporación indígena como una simple aceptación de los ideales corporativos. Cuestiona igualmente las imágenes simplistas de masas indígenas que viven unidas clamando en contra de los supuestos males causados por las corporaciones. Ambas estrategias están siendo empleadas y brindan oportunidades para que un programa político indígena avance en algunas circunstancias, aun cuando sean potencialmente peligrosas para este en otros casos. La adopción de los ideales corporativos es parte de la movilización indígena, pero no podemos separarla de cuestiones más amplias como las iniquidades históricas, el sacrilegio cultural y la representación distorsionada, que sirven también de fundamento para organizar las luchas indígenas. Las estrategias indígenas de incorporación se combinan con esquemas culturales locales, y se ponen en marcha como políticas de identidad y autodeterminación más amplias (Coombe, 1998: capítulo 5). 


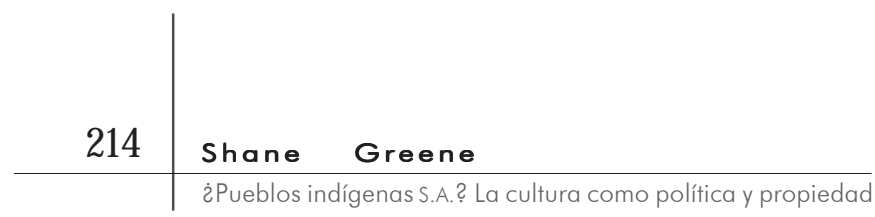

Sin embargo, en lo que se refiere a estas maniobras para privatizar el conocimiento, la cultura y la identidad indígenas, podemos identificar dos peligros. Uno de estos, tal como la historia de la expansión del capitalismo ha dejado en claro, es que la incorporación de los grupos indígenas podría llevar a que algunas clases indígenas monopolizaran la identidad y la propiedad cultural, y a la marginación de otras en lo que respecta a la movilización colectiva político-económica. El otro peligro es que la creación de expectativas exageradas sobre el valor de mercado del conocimiento tradicional, la propiedad cultural y las identidades corporativas continuará sembrando la discordia, no sólo entre los grupos indígenas y los variados agentes del desarrollo y la modernidad, sino también entre los constituyentes indígenas y sus líderes que actúan como brokers. En ambos casos, todavía queda mucho por debatir en la búsqueda de un camino que los saque adelante.

\section{Bibliografía}

Aguilar-Støen, M., Dhillion, S. S. 2003 "Implementation of the Convention on Biodiversity in Mesoamerica: Environment and development aspects”. Environmental Conservation. 30.

Albers-Schönberg, Georg. 1995. "The pharmaceutical discovery process”. En T. Swanson (ed.). Intellectual property rights and biodiversity conservation. Cambridge University Press. Cambridge.

Albó, Xavier. 1991 "El retorno del indio". Revista Andina. 9.

Altman, Jon. 2001 Sustainable development options on aboriginal land: The hybrid economy in the twenty-first century. Australian National University Centre for Aboriginal Economic Policy. Research Discussion Paper 226.

ARtuso, Anthony. 1997. "Capturing the chemical value of biodiversity: Economic perspectives and policy prescriptions". En F. Grifo y J. Rosenthal (eds.). Biodiversity and human health. Island Press. Washington.

Aylward, Bruce. 1995 "The role of plant screening and plant supply in biodiversity conservation, drug development, and health care". En T. Swanson (ed.). Intellectual property rights and biodiversity conservation. Cambridge University Press. Cambridge.

Ballón Aguirre, Francisco. 1988. Política de la supervivencia. Centro de Investigación y Promoción Amazónica. Temas Amazónicos 4. 


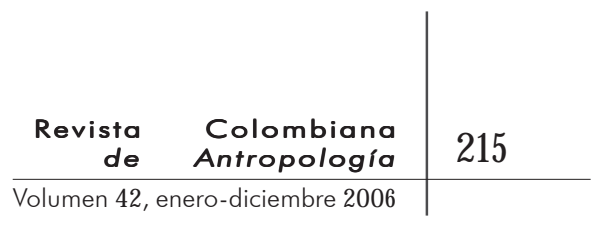

BANERJEE, S. B. 2000. "Whose land is it anyway? National interest, indigenous stakeholders, and colonial discourses: The case of the Jabiluka uranium mine". Organization and Environment. 13 (D).

Bebbington, Anthony, Graham Thiele, Penelope Davies, Martin Prager, HERNANDO Riveros. 1993 Non-governmental organizations and the state in Latin America. Routledge. Londres.

Berlin, Berlin, Alois Ann Berlin. 2002. "Comment on: Maya medicine in the biological gaze: Bioprospecting research as herbal fetishism, by Ronald Nigh". Current Anthropology. 43 (3).

Boyle, James. 1996. Shamans, software, and spleens. Harvard University Press. Cambridge.

Brown, Michael. 2003 Who owns native culture? Harvard University Press. Cambridge.

1998 "Can culture be copyrighted?". Current Anthropology. 39 (2).

. 1993 "Facing the state, facing the world: Amazonia's native leaders and the new politics of identity". L'Homme. 33

BRush, Steven. 1999. "Bioprospecting the public domain". Cultural Anthropology. 14.

. 1996. "Whose knowledge, whose genes, whose rights?". En S. Brush y D. Stabinsky (eds.). Valuing local knowledge. Island Press. Washington.

1994. "A non-market approach to protecting biological resources". En T. Greaves (ed.). Intellectual property rights for indigenous peoples. Society for Applied Anthropology. Norman, Okla.

Brysk, Alison. 2000. From tribal village to global village. Stanford University Press. Stanford.

Carneiro da Cunha, Manuela y Mauro W. B de Almeida. 2000. "Indigenous people, traditional people, and conservation in the Amazon". Daedalus. 129.

CASTREE, N. 2003 "Bioprospecting: From theory to practice (and back again)". Transactions of the Institute of British Geographers. 28.

Chatterjee, Pratap. 1997. "Environment: Peru native peoples' stake in medicinal plant deal". Inter Press Service, Global Information Network. March 6.

Chirif, Alberto, Pedro García, Richard Smith. 1991 El indígena y su territorio son uno solo. Oxfam-Coica. Lima.

Clark, John. 1990. Democratizing development: The role of voluntary organizations. Kumarian Press. West Hartford.

Coica (CoORdinadora de las Organzaciones IndíGenas de la Cuenca Amazónica). 2002. Patente de la planta sagrada ayahuasca. http://www.coica.org/ interna.asp?sp5krp10 (consultada el 30 de enero de 2003). 


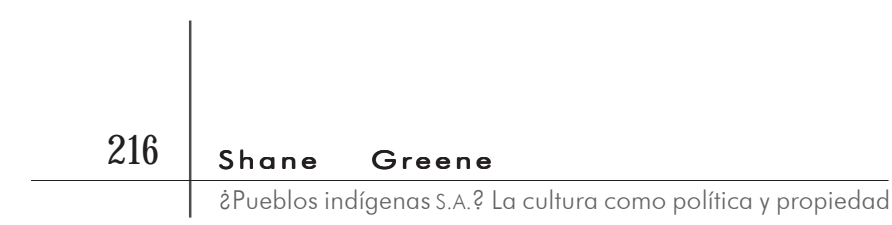

Comaroff, Jean y John Comaroff. 1991 Of revelation and revolution. Vol. 1 University of Chicago Press. Chicago.

Conklin, Beth. 2002. "Shamans versus pirates in the Amazonian treasure chest”. American Anthropologist. 104.

Conklin, Beth y Laura Graham. 1995 “The shifting middle ground: Amazonian Indians and eco-politics”. American Anthropologist. 97.

Conseil, Dominique. 2003 "Aveda announces discontinuation of indigenous product Collection Aveda". http://www.aveda.com/ about/press/indigenous.asp (consultada el 14 de noviembre de 2003).

CoOmbe, Rosemary. 1999. "Intellectual property, human rights, and sovereignty: New dilemmas in international law posed by the recognition of indigenous knowledge and the conservation of biodiversity". Indiana Journal of Global Legal Studies. 6.

1998. The cultural life of intellectual properties. Duke University Press. Durham.

Cox, Paul y Michael Balick. 1994. "The ethnobotanical approach to drug discovery". Scientific American. June.

Dhillion, S. S., H. Svarstad, C. Amundsen, H. C. Bugge. 2002. "Bioprospecting: Effects on the environment and development". AMBIO. 31

Dove, Michael. 1995 "Center, periphery, and biodiversity: A paradox of governance and a developmental challenge”. En S. Brush y D. Stabinsky (eds.). Valuing local knowledge. Island Press. Washington.

Dye, LeE. 2000. “Cures from the forest”. http://www.abcnews.go.com/ sections/science/DyeHard/dyehard000824.html (consultada el 15 de agosto de 2003).

ECONOMIST. 1999. "Shaman loses its magic”. February 20.

Elisabetsky, Elizabeth. 1991 “Folklore, tradition, or know-how?”. Cultural Survival Quarterly. Summer.

Ewen, Alexander. 1994. Voice of indigenous peoples: Native people address the United Nations. Clear Light Publishers. Santa Fe.

FARnsworth, Norman. 1990. "The role of ethnopharmacology in drug development”. En Bioactive compounds from plants. Ciba Foundation Symposium 154. Wiley. Chichester.

Fischer, EDWARD. 1999. "Cultural logic and Maya identity: Rethinking constructivism and essentialism”. Current Anthropology. 40.

Friedman, Jonathan. 1999. "Indigenous struggles and the discreet charm of the bourgeoisie”. Australian Journal of Anthropology. 10 (1). 


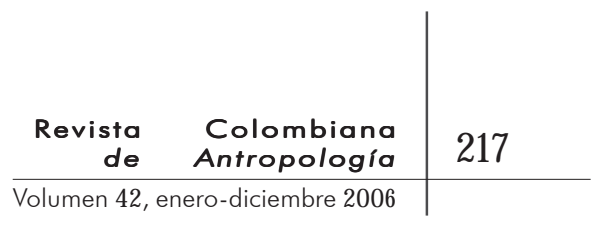

Gale, Dennis. 2001 "Company settles suit over Crazy Horse Malt Liquor". Montana Forum. http://www.montanaforum.com/ rednews/2001/04/27/build/tribal/27liquorsuit.php?nnnp3 (consultada el 20 de enero de 2003).

Gersh, JeFF. 1999. “Capitalism goes green?” San Diego Earth Times. May. http://www.sdearthtimes.com/et0599/et0599s3html (consultada el 3 de octubre de 2003.

GoERING, LaURIE. 1995 "Rain forests may offer new miracle drugs". Chicago Tribune. September 12.

Graham, LaUra. 2002. "How should an Indian speak?”. En K. Warren y J. Jackson (eds.). Indigenous movements, self-representation, and the State in Latin America. University of Texas. Austin.

GreEne, Shane. 2002. "Intellectual property, resources or territory? Reframing the debate over indigenous rights, traditional knowledge, and pharmaceutical bioprospection”. En M. Bradley y P. Petro (eds.). Truth claims: Representation and human rights. Rutgers University Press. New Brunswick.

Gupta, AkHil y James Ferguson. 1992. "Beyond “culture”: Space, identity, and the politics of difference". Cultural Anthropology. 7.

HaAs, Jonathan. 1996. "Power, objects, and a voice for anthropology". Current Anthropology. 37.

HANDLER, Richard. 1985 "On having a culture”. En George Stocking (ed.). Objects and others. Historical Anthropology. 3 University of Wisconsin Press. Madison.

Hardt, Michael y Antonio Negri. 2000. Empire. Harvard University Press. Cambridge.

Hayden, Cori. 2003 "From market to market: Bioprospecting's idioms of inclusion”. American Ethnologist. 30 (3).

_. n. d. "Prospecting's publics". En K. Verdery y C. Humphrey (eds.). Property in question. Berg. In Press. Oxford.

Heller, M. A. y R. S. Eisenberg. 1998. "Can patents deter innovation? The anticommons in biomedical research". Science. 280.

Kearney, Michael y Stefano Varese. 1995 "Latin America's indigenous peoples: Changing identities and forms of resistance". En S. Halebsky y R. Harris (eds.). Capital, power, and inequality in Latin America. Westview Press. Boulder.

King, Steven y Michael Tempesta. 1994. "From shaman to human clinical trials". En D. Chadwick y J. Marsh (eds.). Ethnobotany and the search for new drugs. Ciba Foundation Symposium 185 Wiley. Chichester. 
LAMBReCHT, Bill. 1998. "Bioprospectors find they must be deal-makers as well as scientists". St. Louis Post-Dispatch. October 11

Lewis, Walter, Gerardo Lamas, Abraham Vais-Berg, David Corley y CÉsar Sarasara. 1999. "Peruvian medicinal plant sources of new pharmaceuticals (International Cooperative Biodiversity GroupPeru)". Pharmaceutical Biology. Suppl. 37.

Lewis, Walter y Veena Ramani. n. d. "Ethics and practice in ethnobiology: Analysis of the International Cooperative Biodiversity Group Project in Peru". MS.

Macilwain, Colin. 1998. "When rhetoric hits reality in debate on bioprospecting". Nature. 392.

Meyer, Carrie. 1999. The economics and politics of NGOS in Latin America. Praeger. Westport.

Monsanto. 1998. 1997 report on sustainable development. St. Louis.

Montejo, Victor. 2002. "The multiplicity of Mayan voices: Mayan leadership and the politics of self-representation”. En K. Warren y J. Jackson (eds.). Indigenous movements, self-representation, and the State in Latin America. University of Texas. Austin.

Moran, Katy, Steven King, Thomas Carlson. 2001 "Biodiversity prospecting: Lessons and prospects". Annual Review of Anthropology. 30.

Muehlebach, ANDREa. 2001 "Making place" at the United Nations: Indigenous cultural politics at the U.N. Working Group on Indigenous Populations". Cultural Anthropology. 16.

Niezen, Ronald. 2003 The origins of indigenism. University of California Press. Berkeley.

Nigh, RonALD. 2002. "Maya medicine in the biological gaze: Bioprospecting research as herbal fetishism". Current Anthropology. 43(3).

O'Conner, Tanya. 2000. "Interest drops in rainforest remedies". Health24News 1 July 7.

Orlove, Benjamin, Brush, Stephen. 1996. "Anthropology and the conservation of biodiversity". Annual Review of Anthropology. 25

OsuRI, GoLDIE. 2003 "Discourses of aboriginality and governmentality in Australian television news". MS.

Petras, James. 1997. "Imperialism and NGOs in Latin America". Monthly Review. 49 (7).

Plotkin, Mark. 1993 Tales of a shaman's apprentice. Viking. Nueva York.

Pollack, AndREw. 1992. "Drug industry going back to nature". New York Times. March 5 


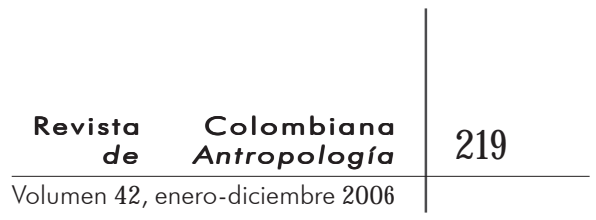

PoSEY, DARReLl. 1990. "Intellectual property rights: What is the position of ethnobiology?”. Journal of Ethnobiology. 10.

Posey, Darrell, Dutfield, Graham. 1996. Beyond intellectual property. International Development Research Centre. Ottawa.

Public Citizen. 2001 "Rx R\&D myths: The case against the drug industry's R\&D "scare card”". http://www.citizen.org (consultada el 1 de agosto de 2001).

Rafi (RuRal AdVANCEMENT Foundation International). 2000. "Stop biopiracy in Mexico!" Rafi News. October 23 http://www.etcgroup.org/ article.asp?newsidp18 (consultada el 9 de febrero de 2003).

— 1995 "Biopiracy update: A global pandemic". Rafi Communiqué, September/October. http://www.etcgroup.org/ article.asp?newsidp206 (consultada el 9 de enero de 2003).

. 1994. "Bioprospecting/biopiracy and indigenous peoples". Rafi Communiqué, November. http://www.etcgroup.org/ article.asp?newsidp212 (consultada el 9 de enero de 2003).

Raghavan, Chakravarthi. 2000. "Neem patent revoked by European Patent Office". http://www.twnside.org.sg/title/revoked.htm (consultada el 28 de enero de 2003).

Ramos, Alcida. 1998. Indigenism: Ethnic politics in Brazil. University of Wisconsin Press. Madison.

Rasnake, Roger. 1988. Domination and cultural resistance. Duke University Press. Durham.

Rausser, G. C. y A. A. Small. 2000. "Valuing research leads: Bioprospecting and the conservation of genetic resources". Journal of Political Economy. 108.

REDFORD, Kent. 1990. "The ecologically noble savage”. Orion Nature Quarterly. 9 (3).

Report of a Special Panel of Experts on the International Cooperative Biodiversity Group. 1997. http://www.nih.gov/fic/opportu- nities/ finalreport.html (consultada el 12 de febrero de 2001).

Request for Applications iCbG. 1997. International Cooperative Biodiversity Group RFA TW-98-001, August 15 National Institutes of Health, National Science Foundation, Foreign Agricultural Service.

Rosenthal, Joshua. 1997. "Integrating drug discovery, bio-diversity conservation, and economic development: Early lessons from the International Cooperative Biodiversity Groups". En F. Grifo y J. Rosenthal (eds.). Biodiversity and human health. Island Press. Washington.

Shiva, VANDANa. 2000. "The neem tree: A case history of biopiracy". http://www.twnside.org.sg/title/pir-ch.htm (consultada el 28 de enero de 2003). 
Smith, Claire, Graeme Ward. 2000. Indigenous cultures in an interconnected world. Allen and Unwin. St. Leonards, Australia.

Smith, Richard Chase. 1996. "Las políticas de la diversidad: Coica y las federaciones étnicas de la Amazonia”. En S. Varese (ed.). Pueblos indios, soberanía y globalismo. Abya-Yala. Quito.

Soejarto, Djaja, Charlotte GyllenhaA, Jacinto Regalado et al. 1999. "Studies on biodiversity of Vietnam and Laos: The UIC-Based ICBG Program”. Pharmaceutical Biology. Suppl. 37.

Stern, Steve. 1982. Peru's Indian peoples and the challenge of Spanish conquest. University of Wisconsin Press. Madison.

Stoll, DAVID. 1999. Rigoberta Menchú and the story of all poor Guatemalans. Westview Press. Boulder.

Strathern, Marilyn. 1996. "Potential property: Intellectual rights and property in persons". Social Anthropology. 4 (1).

Svarstad, H. y S. S. Dhillion (eds.). 2000. Responding to bioprospecting: From biodiversity in the South to medicines in the North. Spartacus Press. Oslo.

Sylvain, RenÉE. 2002. “"Land, water, and truth”: San identity and global indigenism”. American Anthropologist. 104.

Tierney, Patrick. 2000. Darkness in El Dorado. Norton. Nueva York.

Timmerman, Barbara, Wachter, Gerald, Valcic, Susanne et al. 1999. "The Latin American ICBG: The first five years". Pharmaceutical Biology. Suppl. 37.

Tobin, BREndan. 1999a. "Know-how licenses: The Peruvian ICBG project and protection of indigenous collective property rights". Documento presentado en el Seminario internacional de conocimientos tradicionales y recursos genéticos: una oportunidad en el mercado global. Lima, 19-21 de mayo.

1999b. "Protegiendo los derechos de propiedad colectiva: la búsqueda de una solución provisional". En Pablo Ortiz (ed.). Comunidades y conflictos socioambientales. Abya-Yala. Quito.

. 1994. "Putting the commercial cart before the cultural horse”. Documento escrito para la Sociedad Peruana de Derecho Ambiental (SPDA). MS.

. n. d. "Putting the commercial cart before the cultural horse: Part 2". MS.

Turner, Terence. 1993 "The role of indigenous peoples in the environmental crisis: The example of the Kayapo' of the Brazilian Amazon". Perspectives in Biology and Medicine. 36. 
Urban, Greg y Joel Sherzer. 1991 Nation-states and Indians in Latin America. University of Texas Press. Austin.

Van Cott, Donna Lee. 1994. Indigenous peoples and democracy in Latin America. St. Martin's Press. Nueva York.

WARren, Kay. 1998. Indigenous movements and their critics. Princeton University Press. Princeton.

WARren, Kay, JeAn Jackson. 2002. Indigenous movements, selfrepresentation, and the State in Latin America. University of Texas Press. Austin.

WeNDLAND, W. B. 2002. "Intellectual property, traditional knowledge, and folklore: WIPO's exploratory program”. International Review of Industrial Property and Copyright Law. 33

WiSER, GLENN. 2001 “U.S. Patent and Trademark Office rein states ayahuasca patent". http://www.ciel.org/publications/ptodecisionanalysis.pdf (consultada el 15 de diciembre de 2002).

WOLF, ERIC. 1956. "Aspects of group relations in a complex society: Mexico". American Anthropologist. 58.

Wolfe, Patrick. 1999. Settler colonialism and the transformation of anthropology: The politics and poetics of an ethnographic event. Cassell. Londres. 